Article

\title{
Evaluation of Sulfuric Acid-Induced Degradation of Potassium Silicate Activated Metakaolin Geopolymers by Semi-Quantitative SEM-EDX Analysis
}

\author{
Oliver Vogt *(D), Conrad Ballschmiede ${ }^{\circledR}$, Neven Ukrainczyk $(\mathbb{D}$ and Eddie Koenders $(\mathbb{1}$ \\ Institute of Construction and Building Materials, Technical University of Darmstadt, 64287 Darmstadt, Germany; \\ ballschmiede@wib.tu-darmstadt.de (C.B.); ukrainczyk@wib.tu-darmstadt.de (N.U.); \\ koenders@wib.tu-darmstadt.de (E.K.) \\ * Correspondence: vogt@wib.tu-darmstadt.de
}

Received: 3 September 2020; Accepted: 10 October 2020; Published: 12 October 2020

check for updates

\begin{abstract}
Geopolymers are synthesized by mixing powdery solids, rich in amorphous silicon and aluminum species, with an alkaline solution, which leads to the formation of an inorganic alumosilicate network. Their acid resistance is affected by the composition, the porosity, and pore size distribution of the hardened binder as well as the type and concentration of the acidic solution. In the present study, two geopolymer mixtures with varying liquid-to-solid ratios and $\mathrm{Si} / \mathrm{Al}$ ratios were exposed to a sulfuric acid solution $(\mathrm{pH}=1)$ and analyzed after different durations of exposure $(7,14,28,56$, and 70 days) by using a light microscope and scanning electron microscopy with energy-dispersive X-ray spectroscopy (SEM-EDX). SEM-EDX elemental mapping was used to evaluate the degradation from depth profiles of silicon ( $\mathrm{Si}$ ), aluminum $(\mathrm{Al})$, and potassium $(\mathrm{K})$ leaching. The results clearly show the leaching kinetics of potassium and the dealumination of the network. The separate consideration of specific reaction steps in the course of degradation, namely the depth of erosion (DE), the depth of deterioration (DD), and the depth of reaction for certain elements (DR(e)), indicate a combination of chemical and diffusion controlled degradation mechanisms.
\end{abstract}

Keywords: geopolymer; metakaolin; sulfuric acid attack; SEM-EDX; degradation

\section{Introduction}

Geopolymers are synthesized by mixing alumosilicate powders with alkaline solutions. In the process of geopolymerisation, hydroxide $\left(\mathrm{OH}^{-}\right.$from the alkaline solution hydrolyses soluble silicon (Si) and aluminum (Al) species from the alumosilicate powder [1]. The subsequent polycondensation reaction leads to the hardening of the newly formed alumosilicate network [2], which consists of Si and Al tetrahedrons [3] cross-linked by oxygen bridging bonds [1]. The alkali metals $\left(\mathrm{Na}^{+}, \mathrm{K}^{+}\right)$from the alkaline solution are integrated into the network to charge balance the negatively charged aluminum tetrahedrons [4]. Smaller proportions of alkalis that are not integrated into the network remain mobile in the geopolymer pore solution [5]. The alumosilicate network is generally characterized by the Si/Al molar ratio, which according to the Loewenstein-rule [6], has a minimum value of 1.0 [7]. The dissolution of a powdery solid material can also be initialized by using acids like phosphate acids [8,9], which is rarely practiced compared to alkaline activation.

Alkaline activation of slag or other calcium oxide $(\mathrm{CaO})$-rich raw materials are usually referred to as alkali-activated binders (AAB), which also form alumosilicate networks to a certain degree $[10,11]$. Nevertheless, hydration products are also part of the final reaction product $[12,13]$ and the reaction itself resembles more the hydration of Portland cement [14]. Therefore, the term geopolymer is generally 
used to describe $\mathrm{CaO}$-free systems or those with a very low $\mathrm{CaO}$ content, which also corresponds to the definition coined by Davidovits [15]. In order to differentiate between geopolymers and AAB's, classifications were proposed with regard to the type of powdery raw materials [16], as well as with regard to the total calcium content [17]. In the context of this study, the term geopolymer is only used to describe low-CaO systems. If geopolymerisation has to take place at ambient temperature, metakaolin is the most suitable precursor, as it contains a favorable ratio of Si/Al [18,19] and exhibits good reactivity in alkaline media.

The deterioration of concrete based on cement was first mentioned in literature in the year 1990 [20]. In several construction applications like biogas plants [21], sewage plants and sewers [22], and cooling towers of power plants [23,24], the deterioration of concrete is caused by sulfuric acid attack. Due to the sulfuric acid, Portlandit and Calcium silicate hydrate of the hardened binder within the concrete get dissolved and new reaction products like ettringite are built [22], which can further increase the process of deterioration by crack formations and a higher exposed surface of the concrete [25].

The high acid resistance of geopolymers is often mentioned as one of the major advantages of these inorganic binders $[5,26]$. In many cases, comparative studies with hardened geopolymers and hydrated cement have clearly shown that the degree of degradation of hydrated cement is more pronounced than that of geopolymers [27-32], due to the calcium-rich hydration products of cement-based binders [30]. In this context, the differences of mass losses between geopolymers and hardened cement paste after acid exposure can be dramatic [33], and a significantly higher strength loss is found in the case of cement-based binders [34].

Leaching of geopolymer reaction products due to acid attack has been investigated in numerous studies. However, the type and reactivity of powder precursors, variations in liquid-to-solid ratios (1/s), different alkali silicate solutions, and the type and concentration of acidic solution make it difficult to generalize knowledge about the degradation mechanism by comparing results from different publications. The progress of geopolymer corrosion in an acidic environment can vary significantly by applying different powdery precursors [35].

According to Sturm et al. [36], a simplified process of deterioration can be described in three consecutive steps. The leaching of free alkali cations $\left(\mathrm{Na}^{+}, \mathrm{K}^{+}\right)$and/or ion exchange of the charge balancing cations integrated into the geopolymer by hydronium $\left(\mathrm{H}_{3} \mathrm{O}^{+}\right)(1$ st step) is followed by the extraction of aluminum due to the hydrolysis of the $\mathrm{Si}-\mathrm{O}-\mathrm{Al}$ bonds (2nd step) and finally the hydrolysis of $\mathrm{Si}-\mathrm{O}-\mathrm{Si}$ bonds (3rd step).

In literature, studies on acid degradation of geopolymer samples include sulfuric acid [29,31,32,36-45], nitric acid [37,40], hydrochloric acid [44,46-50], and acetic acid [27,28], usually with a $\mathrm{pH}$ in the range of 1 to 3 . As powder precursors, fly ash $[28,29,31,37-42,46]$ or metakaolin $[27,43-45,48-50]$ is used. In some cases, further powdery solids are added to the above-mentioned precursors in smaller quantities.

The assessment of geopolymer degradation due to acid attack is carried out by determining the weight loss $[28,29,31,38,42]$, the change of dimensions [40,42], and the residual strength of exposed samples $[28,29,31,42]$. Further analytical methods comprise Nuclear magnetic resonance spectroscopy (NMR) [51], X-ray diffraction (XRD) [27-29,42,43,50], Fourier-transform infrared spectroscopy (FTIR) [29,42,43,50,51], Micro X-ray computer tomography $(\mu X C T)$ [28], Scanning electron microscopy [29,42,50], and Energy-dispersive X-ray spectroscopy (EDX) [27,31,39,41,51,52].

Evaluating the weight loss after acid exposure to obtain information about the degree of deterioration can be difficult, as the specimen size and geometry will influence the results [40], alongside possible increases in mass due to the formation of new products as a result of precipitation of dissolved species [29].

FTIR has proven to be a useful tool, as it can detect the changes in Si/Al ratios $[29,30]$ of the $\mathrm{H}_{3} \mathrm{O}^{+}$affected geopolymer network, as well as the extent of newly formed $\mathrm{Al}-\mathrm{OH}$ groups due to the hydrolysis of $\mathrm{Si}-\mathrm{O}-\mathrm{Al}$ bonds and, therefore, the depolymerization of the geopolymer [47].

In some cases, XRD analysis of acid exposed specimens revealed the formation of Faujasite [43], silica gel [36], and some other crystalline zeolites [29]. EDX measurements on deteriorated samples, 
in most cases performed as spot analysis, showed changing $\mathrm{Si} / \mathrm{Al}$ and $\mathrm{Na} / \mathrm{Al}$ ratios [52], a dealumination of the network $[27,30]$, and a condensation of silicon-rich polymeric ions [30].

The objective of the present study is to use energy-dispersive X-ray spectroscopy (SEM-EDX) elemental mapping of pristine and deteriorated geopolymers exposed to a sulfuric acid solution $(\mathrm{pH}=1)$ over a period of 70 days as a semi-quantitative tool to investigate the rate of degradation of specimens and classify the different layers having different degrees of degradation. Performing SEM-EDX analysis at different times of sulfuric acid exposure $(7,14,25,56$, and 70 days) and measuring changes in sample geometry, degree of erosion, and deterioration provides useful information about the deterioration process like the depth of erosion, the depth of deterioration, and the depth of reaction for the elements silicon ( $\mathrm{Si}$ ), aluminum (Al), and potassium (K). Replacing conventional concrete for sewers, biogas plants, and cooling towers in power plants by geopolymer concrete could increase the lifetime of these components. To make this possible, the progress of deterioration and the elemental composition after a sulfuric acid attack needs to be fully understood.

\section{Materials and Methods}

\subsection{Materials}

An industrial metakaolin with a density of $2.68 \mathrm{~g} / \mathrm{cm}^{3}$ a high quartz content (39.6\%), and an amorphous amount of $46.0 \%$ was used to synthesize the two geopolymer mixtures. Chemical and mineralogical composition, specific surface area, and particle size distribution have been presented in a previous publication [53]. Impurities like quartz reduced the overall reactivity of the metakaolin but could also have a positive effect in the context of the resistance to acid attack, as those particles could partially block the pores and reduce the extent of alkali cations $\left(\mathrm{Na}^{+}, \mathrm{K}^{+}\right)$leaching from the geopolymer [50]. In addition, higher amounts of quartz reduced the water demand of the powder, which could significantly influence the total porosity and pore size distribution of the hardened binder. Calculation of the amorphous amounts of $\mathrm{Si}$ and $\mathrm{Al}$ in metakaolin by considering the chemical and the mineralogical composition of metakaolin, as proposed by Vogt et al. [53], resulted in the amorphous molar Si/Al ratio of the metakaolin to be 0.89 .

Metakaolin (NEWCHEM GmbH, Baden bei Wien, Austria) was activated by an industrial potassium silicate solution (Wöllner $\mathrm{GmbH}$, Ludwigshafen, Germany) with a molar $\mathrm{SiO}_{2} / \mathrm{K}_{2} \mathrm{O}$ ratio of $1.5, \mathrm{pH} 13.5$, density of $1.51 \mathrm{~g} / \mathrm{cm}^{3}$, viscosity of $20 \mathrm{mPas}$, and a solid content of $45 \%$. Even though in some publications it is claimed that potassium silicate solutions reduced the acid resistance of geopolymers [29,40], compared to metakaolin activated with sodium silicate solution, the low viscosity of the alkaline solution used in this study enabled significantly lower $1 / \mathrm{s}$ ratios with good processability at the same scale.

\subsection{Geopolymer Samples}

Information about the mixing procedure of geopolymer paste can be taken from Vogt et al. [53]. Small prisms $(80 \mathrm{~mm} \times 20 \mathrm{~mm} \times 20 \mathrm{~mm})$ were cast in polyethylene molds, compacted on a vibration table until no more air bubbles could be seen on the surface, and cured at ambient temperature $\left(21^{\circ} \mathrm{C}\right.$, $50 \% \mathrm{RH}$ ) for 28 days, before exposing the specimens to sulfuric acid (Carl Roth $\mathrm{GmbH}+\mathrm{Co}$. KG, Karlsruhe, Germany) at $\mathrm{pH}$ 1. To avoid moisture loss and to keep the samples fully saturated, the molds were wrapped with aluminum adhesive tape, demolded after 1 day, and rewrapped with aluminum tape. To avoid interaction between the aluminum adhesive tape and the sample surface, molds and specimens were wrapped with polyethylene film in a first step before applying the aluminum adhesive tape.

Fully saturated samples guarantee a diffusion-controlled acid attack [28]. The same procedure was performed for larger prisms $(160 \mathrm{~mm} \times 40 \mathrm{~mm} \times 40 \mathrm{~mm})$, which were tested for compressive strength after 28 days of ambient curing $\left(21^{\circ} \mathrm{C}, 50 \% \mathrm{RH}\right)$. In addition to the $1 / \mathrm{s}$ ratios, Table 1 shows the 
molar Si/Al and K/Al ratios of the two geopolymer mixtures of this study, MK54 and MK60, the number in the designation representing the $1 / \mathrm{s}$ ratio.

Table 1. Liquid/solid ratios (l/s), molar Si/Al ratios (Si/Al $\mathrm{tot}_{\text {tot }}$ total amount of $\mathrm{Si}$ and $\mathrm{Al}$ from metakaolin; $\mathrm{Si} / \mathrm{Al}_{\mathrm{am}}$ : amorphous $\mathrm{Si}$ and $\mathrm{Al}$ of metakaolin) and molar $\mathrm{K} / \mathrm{Al}$ ratios $\left(\mathrm{K} / \mathrm{Al}_{\text {tot }}\right.$ : total amount of $\mathrm{Al}$ from metakaolin; $\mathrm{K} / \mathrm{Al}_{\mathrm{am}}$ : amorphous $\mathrm{Al}$ of metakaolin) of MK54 and MK60. Chemical composition and amorphous amount of $\mathrm{Si}$ and $\mathrm{Al}$ for $\mathrm{Si} / \mathrm{Al}$ ratios were taken from Vogt et al. [53].

\begin{tabular}{cccccc}
\hline Name & $\mathbf{1 / s}[-]$ & $\mathbf{S i} / \mathbf{A l}_{\mathbf{a m}}[-]$ & $\mathbf{S i}_{\mathbf{A}} \mathbf{A l}_{\text {tot }}[-]$ & $\mathbf{K} / \mathbf{A l}_{\mathbf{a m}}[-]$ & $\mathbf{K}_{\mathbf{A l}} \mathbf{A l}_{\text {tot }}[-]$ \\
\hline MK54 & 0.54 & 1.37 & 2.51 & 0.64 & 0.50 \\
\hline MK60 & 0.60 & 1.42 & 2.55 & 0.71 & 0.55 \\
\hline
\end{tabular}

$\mathrm{Si} / \mathrm{Al}_{\mathrm{am}}$ contains $\mathrm{Si}$ from potassium silicate solution and amorphous $\mathrm{Si}$ and $\mathrm{Al}$ from metakaolin. $\mathrm{Si} / \mathrm{Al}_{\text {tot }}$ contains $\mathrm{Si}$ from potassium silicate solution and the total amount of $\mathrm{Si}$ and $\mathrm{Al}$ from metakaolin. $\mathrm{K} / \mathrm{Al}_{\mathrm{am}}$ and $\mathrm{K} / \mathrm{Al}_{\text {tot }}$ contain $\mathrm{K}$ from potassium silicate solution and amorphous $\mathrm{Al}$ from metakaolin $\left(\mathrm{K} / \mathrm{Al}_{\mathrm{am}}\right)$ and the total amount of $\mathrm{Al}$ from metakaolin $\left(\mathrm{K} / \mathrm{Al}_{\mathrm{tot}}\right)$, respectively.

Liquid ' 1 ' comprises the total mass of potassium silicate solution (water and dissolved alkali-silicates), while 's' represents the total mass of powder metakaolin. Thus the mix designs of MK54 and MK60 contain differing amounts of water and percentages of $\mathrm{SiO}_{2}$ and $\mathrm{K}_{2} \mathrm{O}$ from the potassium silicate solution. Expressed in mass per unitary volume, $1 \mathrm{dm}^{3}$ of MK54 paste comprises $1.369 \mathrm{~kg}$ of metakaolin and $0.739 \mathrm{~kg}$ of potassium silicate solution, respectively $1.298 \mathrm{~kg}$ of metakaolin and $0.779 \mathrm{~kg}$ of potassium silicate solution for $1 \mathrm{dm}^{3}$ of MK60 paste.

\subsection{Characterization Methods of Unexposed Samples}

To verify the suitability of the 2 geopolymers as potential building materials, setting time and compressive strength were determined. Compressive strength was tested with half prisms $(80 \mathrm{~mm} \times 40 \mathrm{~mm} \times 40 \mathrm{~mm})$ at a loading rate of $2.4 \mathrm{kN} / \mathrm{s}$, following the guidelines of DIN EN 196-1 [54]. An automatic Vicat needle instrument (ToniSET One, Toni Technik, Berlin, Germany) was applied for determining initial and final setting time. To quantify the difference in porosity and pore size distribution, mercury intrusion porosimetry (MIP) was conducted with a Pascal 440 Mercury Porosimeter (ThermoFisher, Waltham, MA, USA) on 28 days cured specimens. For MIP measurements, samples were immersed in liquid nitrogen and dried until mass constancy with a freeze drier (Lyotrap, LTE Scientific Ltd., Oldham, UK).

Qualitative powder X-ray diffraction was performed on 28 days cured specimens and after 7, 14, 28, 56, and 70 days of exposure to sulfuric acid, with a Bruker D2 Phaser (Hamburg, Germany). Operating conditions were set to $40 \mathrm{kV}$ and $10 \mathrm{~mA}$, configured with $\mathrm{CuK} \alpha 1$,2 radiation and linear LYNXEYE detector, with 5 degrees opening, goniometer measurement circle $283 \mathrm{~mm}$, primary optics with $0.4 \mathrm{~mm} 220$ fixed slit, 2.5 degrees soller slits, and using Ni-filter in secondary optics. All samples were measured from 5 to 70 degrees $(2 \theta)$ with 0.02 step size and measurement time of 2 s/step. Powder samples of exposed geopolymers for XRD analysis were prepared by crushing and grinding only the deteriorated layer of the exposed samples.

The elemental composition of unexposed samples MK54 and MK60 were investigated by SEM-EDX measurements to calculate the ratios $\mathrm{Si} / \mathrm{Al}$ and $\mathrm{K} / \mathrm{Al}$ before exposure to sulfuric acid and to obtain the reference values $\operatorname{ref}(\min )$ and $\operatorname{ref}(\max )$, which were used to determine the depth of reaction for a certain element (see Section 2.7). The procedure for sample preparation before SEM-EDX analysis is described in Section 2.5. Section 2.6 contains relevant information about the SEM-EDX measurements.

\subsection{Exposure to Sulfuric Acid}

A Sulfuric acid solution was prepared with deionized water and concentrated sulfuric acid (96\%). After curing the geopolymer samples for 28 days, exposure to sulfuric acid solution started at an initial 
$\mathrm{pH}$ of 1 over a period of 70 days. Specimens in the exposure tank had a minimum distance of $1 \mathrm{~cm}$ from each other and to the walls of the tank (Figure 1). MK54 and MK60 were stored in separate tanks. The volume ratio of acid solution-to-specimens was 22. During the test, the solution was not exchanged, which corresponds to a real field application, but the $\mathrm{pH}$ was kept constant at approximately 1 by adding a 50\% concentrated sulfuric acid solution manually at least once a day. The $\mathrm{pH}$ of a solution was measured with a pH meter (Hanna pH 211, Vöhringen, Germany) at least once a day, as an average of two replicate setups. Corroded geopolymers were analyzed with different characterization methods after $7,14,28,56$, and 70 days of exposure to sulfuric acid. No mechanical stirring of the acid solution was performed, since height-related differences in sulfuric acid concentration were not to be expected, due to the complete dissociation of sulfuric acid, and an acceleration of the degradation process, which should be prevented [55]. Manual stirring of the solution was done daily, before and after the post acidification with 50\% concentrated sulfuric acid.

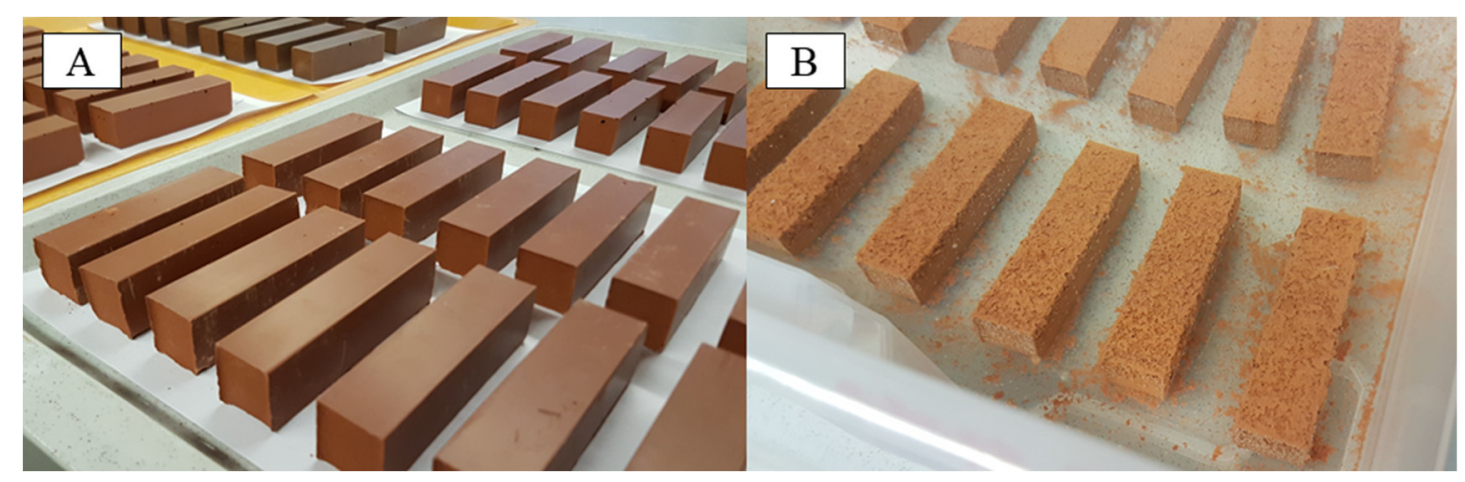

Figure 1. Geopolymer prisms MK54 $(80 \mathrm{~mm} \times 20 \mathrm{~mm} \times 20 \mathrm{~mm})$ before $(\mathbf{A})$ and after $17 \mathrm{~h}$ in sulfuric acid solution ( $\mathrm{pH}$ 1) (B), where the corrosion due to the erosion of the geopolymer specimen surface is already visible.

\subsection{Sample Preparation after Sulfuric Acid Exposure}

In order to perform SEM-EDX measurements, specimens were carefully removed after exposure to sulfuric acid and dried at $40{ }^{\circ} \mathrm{C}$ until mass constancy. Cross-sections of $1 \mathrm{~cm}$ thickness were dry cut with a low-speed diamond-tipped precision cutter (IsoMetTM, Buehler, Esslingen am Neckar, Germany). The cross-sections were impregnated with epoxy resin under vacuum and heated at $40{ }^{\circ} \mathrm{C}$ for $24 \mathrm{~h}$ to cure the resin. The polishing of specimens was performed with a resin-bonded diamond disc (hardness range HV 150 to 2000) from a polishing machine (LaboForce-100, Struers, Cleveland, $\mathrm{OH}, \mathrm{USA}$ ) to reveal the surface of the specimens (rotational speed $300 \mathrm{rpm}$ ). For a second polishing, an automated polycrystalline diamond spray was used at a rotational speed of $150 \mathrm{rpm}(9 \mu \mathrm{m}, 3 \mu \mathrm{m}$, and $1 \mu \mathrm{m}$ size).

\subsection{Characterization of Sulfuric Acid Exposed Samples}

The revealed degradation mechanism due to exposure to sulfuric acid was analyzed by measuring the eroded and corroded layer of epoxy embedded specimens. The thickness of the eroded layer was obtained by taking into account the dimensions of specimens before and after exposure to sulfuric acid. The thickness of the deteriorated layer was measured using a light microscope (VHX-600, Keyence, Neu-Isenburg, Germany). Each mean value resulted from eight individual measurements, four values on each side of the specimen (left and right). Elemental mapping, obtained by scanning electron microscopy with energy-dispersive X-ray spectroscopy (SEM-EDX), were used to evaluate the leaching and depolymerization of the alumosilicate network. SEM-EDX investigations were performed with a Zeiss EVO LS25 SEM (Jena, Germany) and an EDX detector (EDAX, Ametek, Berwyn, PA, USA) under low-vac. modus at 0.1 mbar to prevent charging effects on the samples. All samples were studied at $2.0 \mathrm{nA}$ probe size and $15.0 \mathrm{kV}$ accelerating voltage with a 100x magnification for EDX. Elemental 
mappings were conducted to determine the spatial element distribution of silicon (Si), aluminum (Al), and potassium $(\mathrm{K})$ in the cross-section of sulfuric acid exposed epoxy embedded specimens. Elemental mappings were performed at a dwell time of $200 \mu$ s for each pixel (512 $\times 400$ pixels in total) with a repetition rate of 128 .

To minimize the influences caused by interactions between the sample surface and electron beam, ZAF correction was applied. The ZAF correction uses an algorithm which accounts for Z-the atomic number, $\mathrm{A}$ - the absorption correction, and $\mathrm{F}$ - the fluorescence correction. These corrections are used for matrix effects (e.g., differences in mean atomic number, in the absorption of X-rays, and production of $\mathrm{X}$-rays or X-ray fluorescence). In combination with internal standards, an error is quantifiable. However, due to the use of these internal device standards and not sample-specific standards, the results should be considered as semi-quantitative [56].

\subsection{Position of Elemental Mappings and Terminology of Experimental Results}

The evaluation and presentation of the experimental results in this study are carried out according to a specific procedure (see Figure 2). The terms "depth of erosion" (DE), "depth of reaction" (DR(e)), and "depth of deterioration" (DD) have already been used by König et al. [28,55], where DD is composed of DE and DR. In the present study, DE, DR, and DD are interpreted differently.

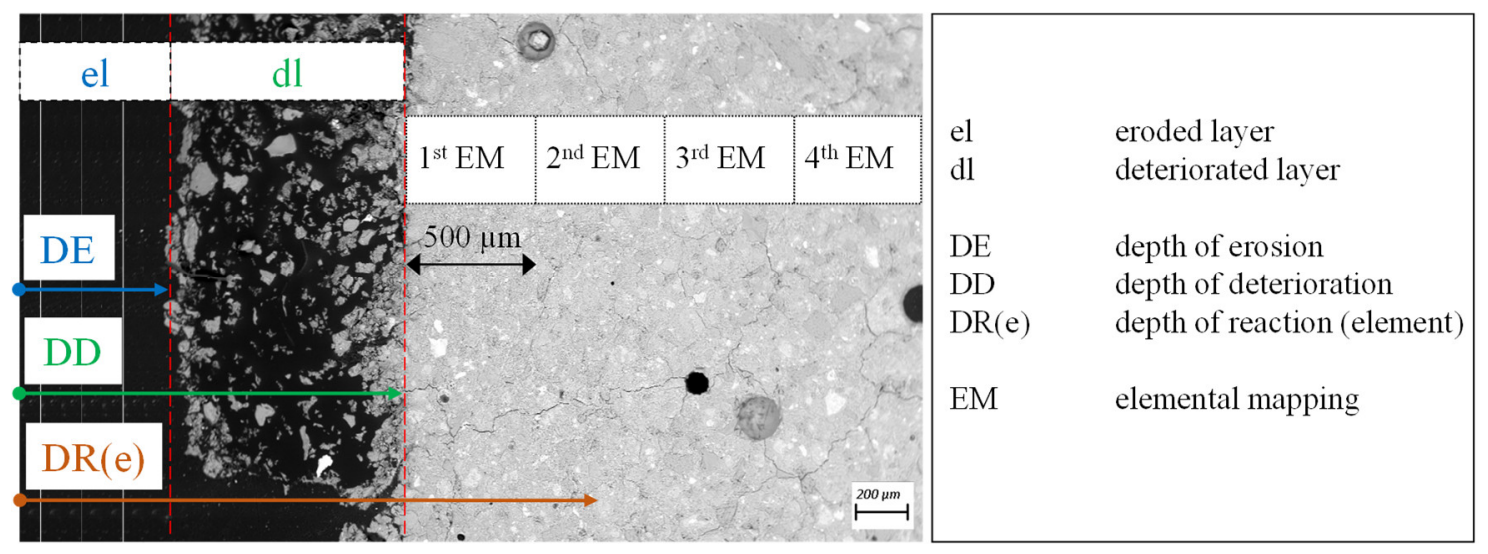

Figure 2. Description of a used terminology: eroded layer (el), deteriorated layer (dl), depth of erosion (DE), depth of deterioration (DD), and depth of reaction for specific elements (DR(e)). The positioning of SEM-EDX elemental mapping (EM) for profile evaluation of the sulfuric acid-induced degradation.

All previously mentioned depths refer to the pristine surface (not exposed to sulfuric acid), i.e., the outer dimensions of the specimen. DE includes the thickness of the eroded layer (el), DD comprises the eroded layer and the deteriorated layer (dl). DR(e) includes DD and the corresponding depth of reaction for a specific element, which will be explained below. DR(e), which results from EDX elemental mapping, was measured for Si (DR(Si)), Al (DR(Al), and K (DR(K)). The first elemental mapping was conducted at the end of DD, where the following mappings approached the core of the specimen. The deteriorated layer was not analyzed by EDX, due to significantly higher porosity and the resulting inaccuracy of the measurements, which was detected by preliminary testing.

Figure 3 illustrates the procedure for determining DR(e), using the example of aluminum. The region of interest along the specimen's depth was divided into $500 \mu \mathrm{m}$ sections ("elemental mapping (EM) width", Figure 3). For each section a mean and corresponding absolute error was calculated, which results in the graphs for DR(e). The red dotted horizontal lines in Figure 3 (ref $f_{\max }$ and ref $_{\min }$ ) were the minimum and maximum percentages of the element of the original sample (no exposure to sulfuric acid) after 28 days of curing. Minimum and maximum values were obtained by considering the mean value and the corresponding absolute error (i.e., mean \pm one standard deviation) from element mapping. DR(e), in this case, $\mathrm{DR}(\mathrm{Al})$, was determined by the mean value of the elemental 
mapping, at which the ref $\mathrm{min}_{\text {min }}$ line in Figure 3 was reached. Using the example of $\mathrm{Al}, \mathrm{DR}(\mathrm{Al})$ is the spot at a certain specimen depth where the dealumination effect (i.e., the lower percentages of $\mathrm{Al}$ in exposed sample area than in the original sample) of the alumosilicate network had ceased, as the Al-concentration reached the values of the unexposed sample.

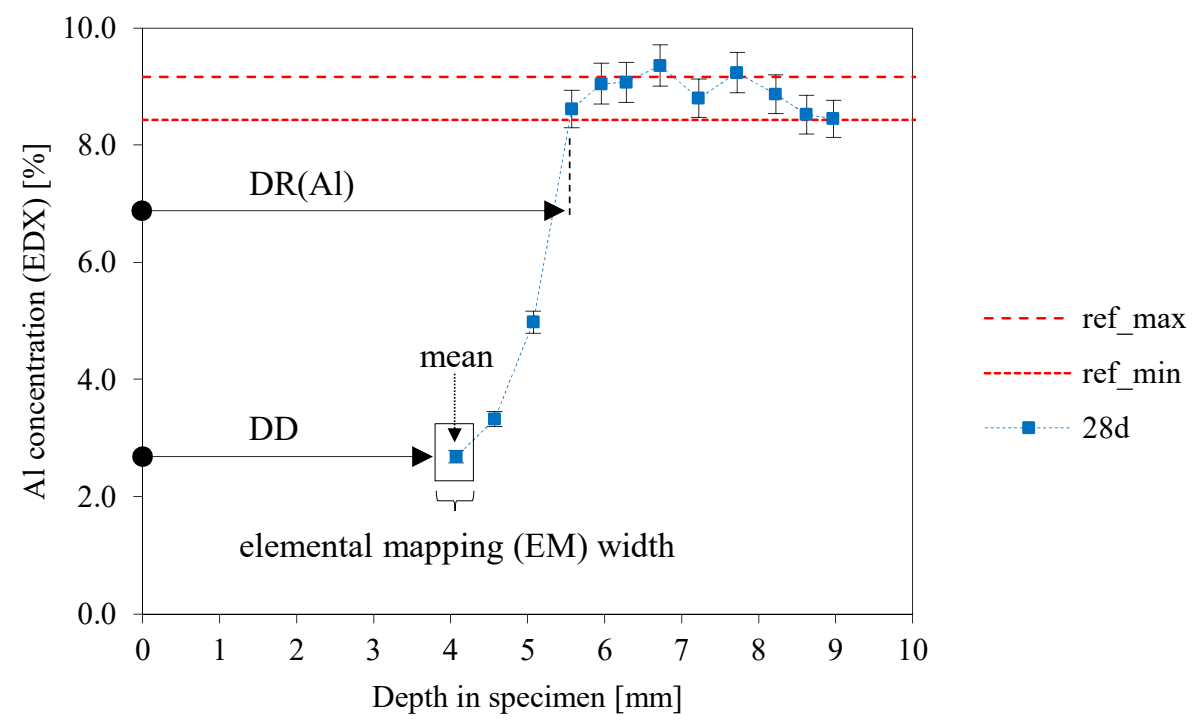

Figure 3. Method of determining the depth of reaction DR(e) of geopolymer elements (SEM-EDX elemental mapping).

\section{Results}

\subsection{Physical Properties of Unexposed Samples}

The evolution of compressive strength has been presented in a previous publication [53]. MK54 and MK60 reached 58.2 MPa and 53.6 MPa, respectively, after 28 days. Compressive strength after 1 day revealed that both geopolymer formulations are highly reactive systems, as the values were only slightly smaller compared to 28-day compressive strength (51.4 MPa for MK54, 48.2 MPa for MK60). The initial and final setting for MK54 is $127 \mathrm{~min}$ and $147 \mathrm{~min}$, for MK60 $160 \mathrm{~min}$ and $190 \mathrm{~min}$. Compared to strength and setting, porosity might be more relevant for evaluating the results of sulfuric acid exposed specimens. Table 2 shows the total mercury intruded porosity and pore size distribution of samples after 28 days of ambient curing.

Table 2. Total $\mathrm{Hg}$ intruded porosity and percentage of pore sizes (MIP) for MK54 and MK60 after 28 days of ambient curing $\left(21^{\circ} \mathrm{C}, 50 \% \mathrm{RH}\right)$.

\begin{tabular}{|c|c|c|c|c|c|}
\hline \multirow{2}{*}{ Name } & \multirow{2}{*}{$\begin{array}{c}\text { Total Porosity } \\
{[\%]}\end{array}$} & \multicolumn{4}{|c|}{ Pore Size Distribution by Volume Ratio [\%] } \\
\hline & & $<10 \mathrm{~nm}$ & $10 \mathrm{~nm}-20 \mathrm{~nm}$ & $20 \mathrm{~nm}-50 \mathrm{~nm}$ & $50 \mathrm{~nm}-100 \mathrm{~nm}$ \\
\hline MK54 & 25.6 & 31.4 & 36.8 & 13.1 & 15.9 \\
\hline MK60 & 26.4 & 28.3 & 30.6 & 27.3 & 13.6 \\
\hline
\end{tabular}

Apart from total porosity, there was a more noticeable difference in pore size distribution. The higher 1/s ratio of MK60 results in a shift of the pore size distribution towards bigger pores, which coincided with the results from the literature [57,58]. The biggest change could be observed for pores $<10 \mu \mathrm{m}$ and in the range of $20 \mu \mathrm{m}$ to $50 \mu \mathrm{m}$, where the shift was most pronounced. 


\subsection{Elemental Mapping of Unexposed Geopolymers}

SEM-EDX elemental mapping from unexposed samples was used to evaluate DR(e), for determining the reference values ref $_{\min }$ and ref $_{\max }$ (Figure 3) and for comparing the SEM-EDX elemental composition with the chemical composition obtained by X-ray fluorescence (Si/Al tot, Table 1). Figure 4 reveals the percentage of element distribution for Si, Al, and K, obtained by SEM-EDX.

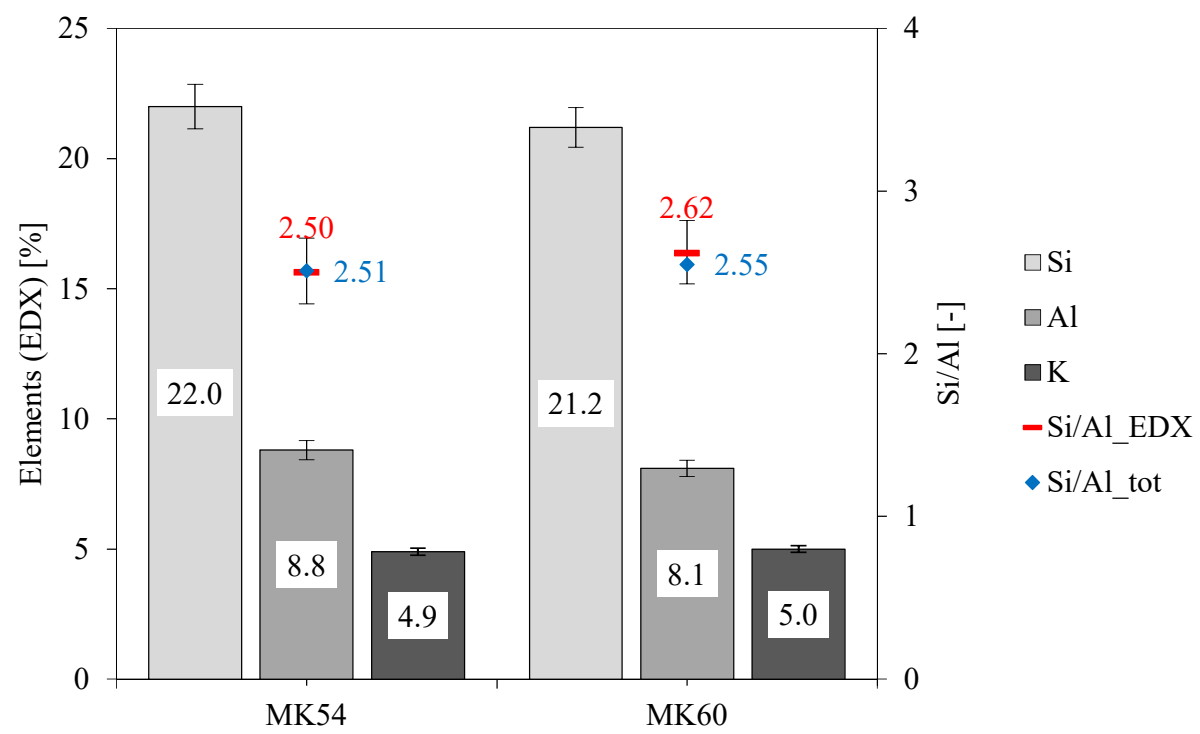

Figure 4. Percentage element distribution for $\mathrm{Si}, \mathrm{Al}, \mathrm{K}$, and $\mathrm{Si} / \mathrm{Al}$ ratios obtained from SEM-EDX elemental mapping and from the chemical composition of geopolymer formulation ( $\left.\mathrm{Si} / \mathrm{Al}_{\text {tot }}\right)$ for geopolymers MK54 and MK60.

The relative errors of the elements obtained by SEM-EDX analysis for MK54 were 3.9\% (Si), 4.2\% $(\mathrm{Al})$, and $2.8 \%(\mathrm{~K})$, and $3.6 \%(\mathrm{Si}), 3.8 \%(\mathrm{Al})$ and $2.5 \%(\mathrm{~K})$ for MK60. With these values, the absolute errors of elements could be calculated, which were $0.86 \%(\mathrm{Si}), 0.37 \%(\mathrm{Al})$, and $0.14 \%(\mathrm{~K})$ for $\mathrm{MK} 54$, and $0.76 \%(\mathrm{Si}), 0.31 \%(\mathrm{Al})$ and $0.13 \%(\mathrm{~K})$ for MK60. Furthermore, mean Si/Al EDx ratios of $2.50(0.21)$ for MK54 and 2.62 (0.20) for MK60 could be calculated (absolute errors in brackets), also illustrated in Figure 4 as $\mathrm{Si} / \mathrm{Al}_{\mathrm{EDX}}$.

The higher $\mathrm{Si} / \mathrm{Al}$ ratio of sample MK60 was due to the lower amount of $\mathrm{Al}$ from metakaolin, as the increase of 1/s from 0.54 to 0.60 resulted from a lower amount of metakaolin in the formulation. This was also confirmed by the lower amount of Si in MK60 obtained by SEM-EDX measurement.

Since the deviation of $\mathrm{Si} / \mathrm{Al}_{\mathrm{EDX}}$ and $\mathrm{Si} / \mathrm{Al}_{\text {tot }}$ was very small for both geopolymers, ratios obtained by SEM-EDX elemental mapping were considered accurate, especially in the context of ref $f_{\text {min }}$ and ref $_{\text {max }}$ for determining $\mathrm{DR}(\mathrm{e})$ (see Figure 3). Calculated $\mathrm{K} / \mathrm{Al}_{\text {tot }}$ ratios from the chemical composition of precursors and mass percentages in the geopolymers led to 0.50 for MK54 and 0.55 for MK60, while ratios obtained by SEM-EDX are 0.56 (0.14) for MK54 and 0.62 (0.13) for MK60 (absolute errors in brackets).

The element distribution in MK54 was illustrated in the EDX elemental mapping in Figure 5, showing the superposition of all chosen elements (upper-middle image) as well as elements $\mathrm{C}$ (carbon), O (oxygen), Al (aluminum), Si (silicon), S (sulfur), and K (potassium) separately. Superposition of all elements and the C-image showed that carbon is generally associated with large pores or defects in the structure of geopolymer, as those regions are filled with epoxy resin from sample preparation and therefore are detected as carbon by SEM-EDX. Comparing Si- and Al-images indicated that the high quartz content of metakaolin was more or less evenly distributed in the geopolymer gel. Bright purple spots in the Si-image were quartz particles, which were dark spots in the corresponding Al-image, without showing signs of the color representing Al. This proved that the bright purple spots were not a geopolymer reaction product, as this would also be visualized in the Al-image. The quartz particles 
embedded in the geopolymer gel did not dissolve in an alkaline media, at least not to any relevant extend, and remain mainly as an inert filler within the hardened binder [59-61]. This fact led to the large deviations of $\mathrm{Si} / \mathrm{Al}$ ratios as represented in Table $1 . \mathrm{Si} / \mathrm{Al}_{\text {tot }}$ was calculated from the chemical composition of metakaolin with a quartz content of $39.6 \% . \mathrm{Si} / \mathrm{Al}_{\mathrm{am}}$ only considered the amorphous $\mathrm{Si}$ and $\mathrm{Al}$ from metakaolin. For this reason, the value was close to 1, which corresponded to the $\mathrm{Si} / \mathrm{Al}$ ratio of pure (meta) kaolinite.

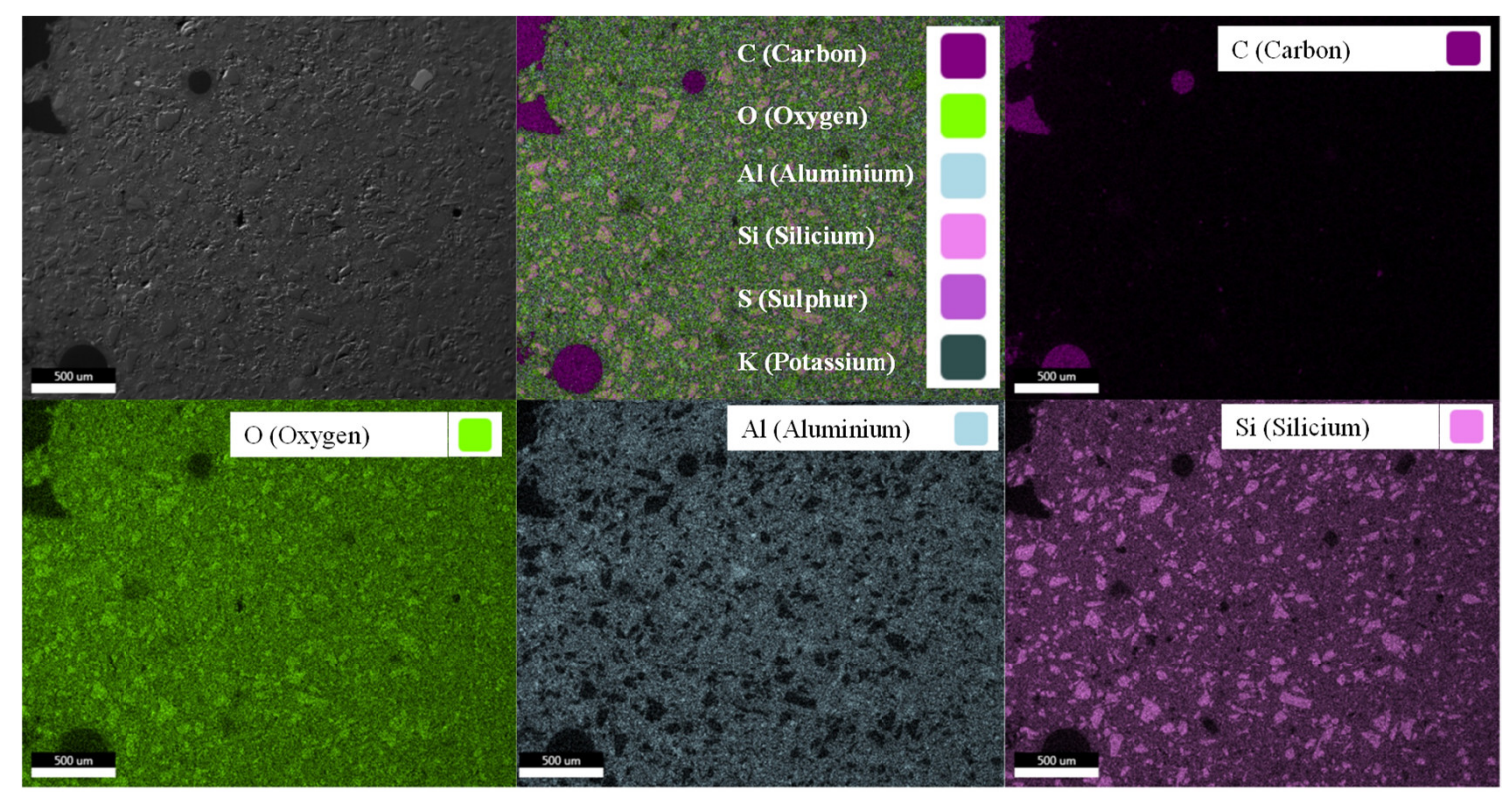

Figure 5. SEM-EDX elemental mapping of epoxy resin embedded cross-section of pristine Geopolymer MK54, i.e., before exposure to sulfuric acid (superposition of elements in the top center image; SEM image in top left image).

\subsection{SEM Images of Sulfuric Acid Exposed Samples}

SEM backscatter images of geopolymers MK54 and MK60 after 7, 28, and 70 days of exposure to sulfuric acid are presented in Figure 6. Each of the 6 images clearly showed the deteriorated layer of the geopolymers on the left side of the images, which was characterized by a higher proportion of darker spots due to the higher porosity of these parts of the sample. In addition to the higher porosity, cracks of different sizes were present in each sample's deteriorated layer. At the depth of deterioration (DD), further cracks were visible, mainly aligned parallel to the transition zone between the deteriorated layer and the apparently intact core of the sample.

Cracks were not only present in the region of the deteriorated layer but also in the apparently intact core of the samples, which may be induced by temperature drying of the specimens before sample preparation with epoxy resin and EDX measurements. Due to the high viscosity of metakaolin geopolymer pastes, the complete removal of air entrapments in the fresh paste by applying a vibration table could not be achieved, which can be seen at the occasional dark spots in the region of the apparently intact core, representing air pores. 


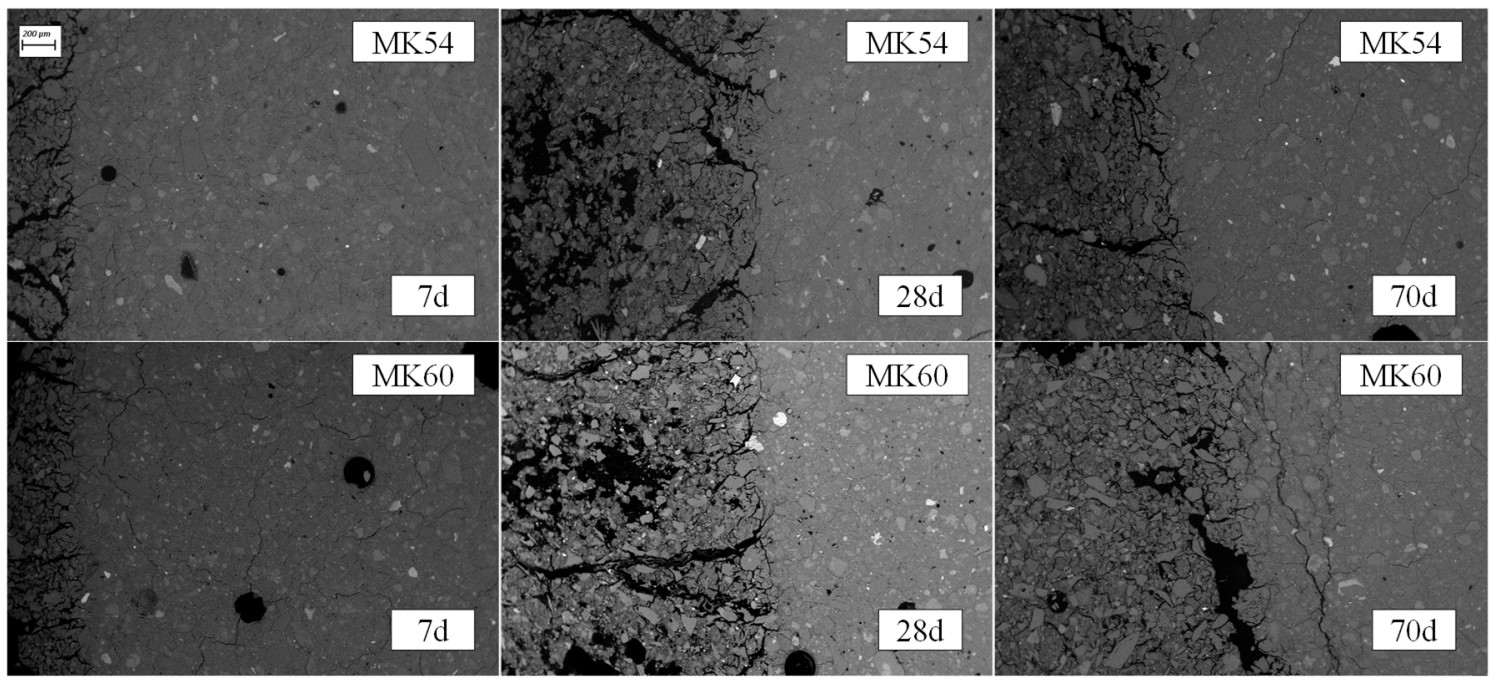

Figure 6. SEM backscatter images of geopolymers MK54 and MK60 after 7 (7 d), 28 (28 d), and 70 (70 d) days of exposure to sulfuric acid, the left side of each image showing the deteriorated layer.

\subsection{Elemental Mapping of Sulfuric Acid Exposed Geopolymers}

Elemental mapping of sulfuric acid exposed geopolymer samples (Figure 7) showed deterioration of the geopolymer surface exposed to sulfuric acid (upper left image), with higher porosity and micro-cracks.

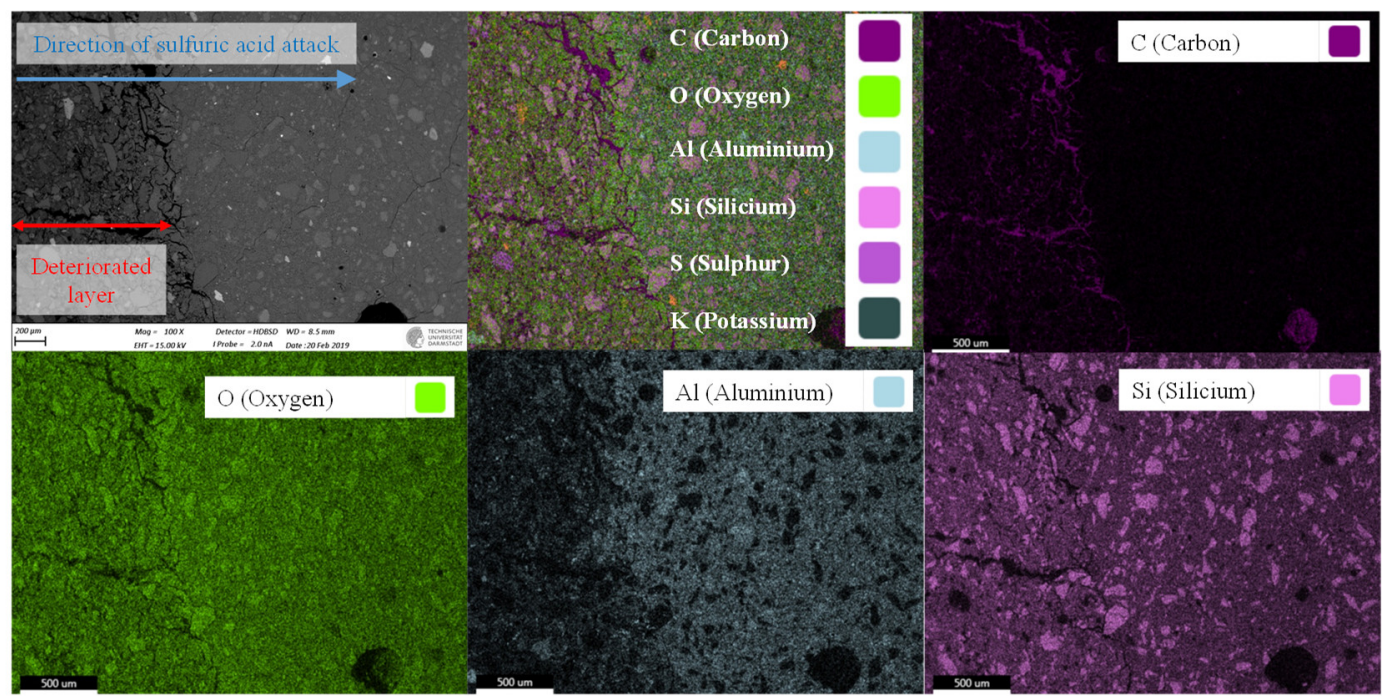

Figure 7. SEM-EDX elemental mapping of epoxy resin embedded cross-section of Geopolymer MK54 after exposure to sulfuric acid, showing high porosity within the deteriorated layer as well as varying element composition due to sulfuric acid attack.

Superposition of all elements (upper-middle image) and C-image visualized the acid attack induced porosity, as these areas were filled with epoxy resin from the sample preparation. Superposition of all elements and Si-image also suggested that quartz particles were not dissolved significantly due to sulfuric acid exposure. Comparing the Al-image with the Si-image gave a first impression of the deterioration process. Within the deteriorated layer, $\mathrm{Al}$ was present to a lesser extent, visualized by differences in color between the deteriorated layer and the core of the sample. Those differences in color were not visible in the Si-image, indicating that $\mathrm{Si}$ was far less dissolved then $\mathrm{Al}$. 


\section{5. $p H$ of Sulfuric Acid Solution}

The initial $\mathrm{pH} 1$ of the sulfuric acid solution could not be maintained constant for the entire duration of specimen exposure as certain fluctuations could not be avoided (Figure 8). Within the first 36 days of exposure, the $\mathrm{pH}$ of the solution increased daily, which was compensated by the addition of $50 \%$ sulphuric acid. As a result, the $\mathrm{pH}$ value could be kept almost constant in a range of 0.9-1.1. Apart from a few single days, $\mathrm{pH}$ was always above 1.0. The mean $\mathrm{pH}$ over 70 days of exposure was 1.03 for both geopolymer formulations. The steady increase of $\mathrm{pH}$ after post-acidification illustrated the neutralization of sulphuric acid by the alkaline pore solution of the geopolymer.
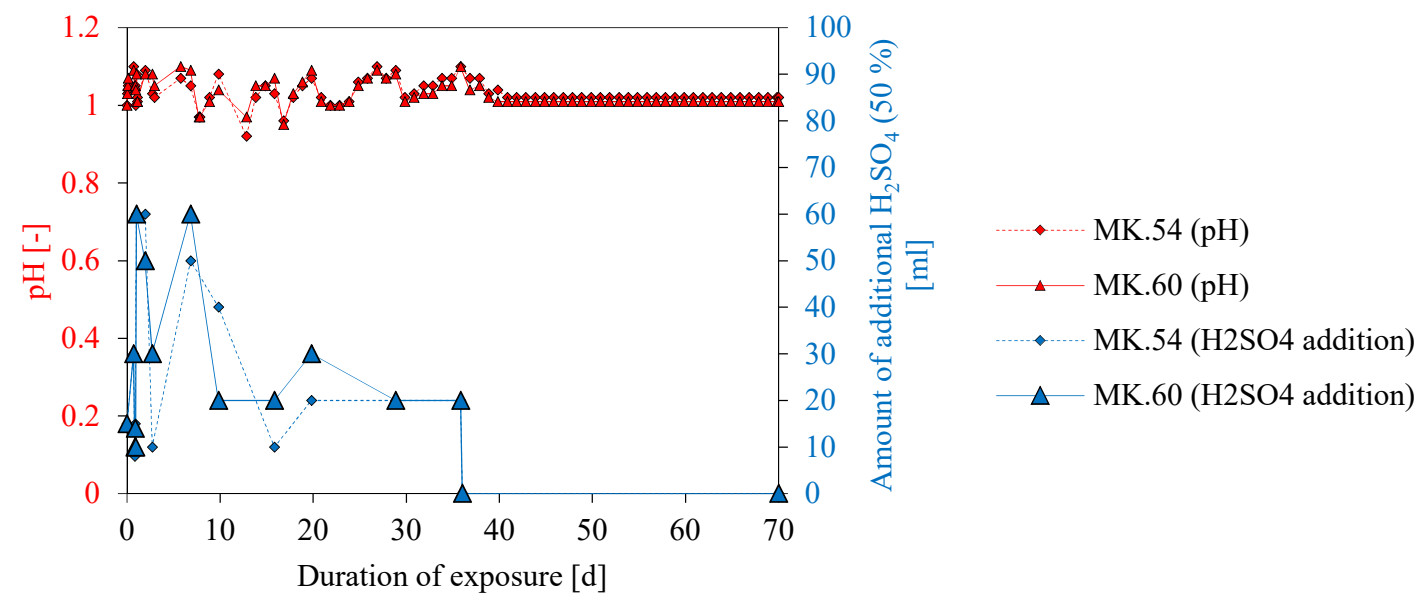

Figure 8. $\mathrm{pH}$ of the sulfuric acid solution for MK54 and MK60 over the complete exposure time (70 days) and amount of sulfuric acid (50\%) addition to maintain a constant $\mathrm{pH}$ in the range of 1 .

Due to the interaction of the alkaline pore solution and acidic solution, $\mathrm{H}^{+}$of the acidic solution got consumed. As sulfuric acid is a strong acid without buffering capacity, in this case, the acidic solution got neutralized and must be post acidified to keep the $\mathrm{pH}$ at a constant level. [55] At the beginning of the sample exposure in sulfuric acid, large amounts of $50 \%$ sulfuric acid had to be added (see Figure 8), indicating a strong neutralization reaction. Lower amounts of $50 \%$ sulfuric acid for post acidification at later stages of exposure resulted from the extraction of samples for SEM-EDX analysis $(7,14.28,56$, and 70 days), as well as the lower neutralization rate of the samples due to the initially higher leaching of potassium [45]. Leaching of $\mathrm{Si}$ and $\mathrm{Al}$ from the geopolymer samples could also neutralize the $\mathrm{pH}$ of sulfuric acid, as $\mathrm{Si}$ and $\mathrm{Al}$ could react with $\mathrm{OH}^{-}$to form $\mathrm{Si}(\mathrm{OH})^{4} \mathrm{Al}(\mathrm{OH})^{3}$ and other speciation complexes in solution. However, the consumption of $\mathrm{OH}^{-}$, in this case, might be low. [62] Post-acidification was stopped after 36 days, as the $\mathrm{pH}$ remained constant until the end of exposure (70 days).

\subsection{Eroded and Deteriorated Layer}

Figure 9 illustrates the epoxy embedded and unexposed sample $(0 \mathrm{~d})$ of MK54, and the sulfuric acid exposed samples $(7,28$, and 70 days) with the clearly visible deteriorated layer ( $\mathrm{dl})$. The deteriorated layers were characterized by a higher porosity, visual cracks, and a different color intensity compared to the core of the samples. Cracks in the deteriorated layer have also been reported in other publications and were explained by shrinkage of the deteriorated layer $[40,47]$. Whether the shrinkage occurred during exposure to sulfuric acid or subsequent drying at $40{ }^{\circ} \mathrm{C}$ during sample preparation, could not be stated clearly in the present study. 


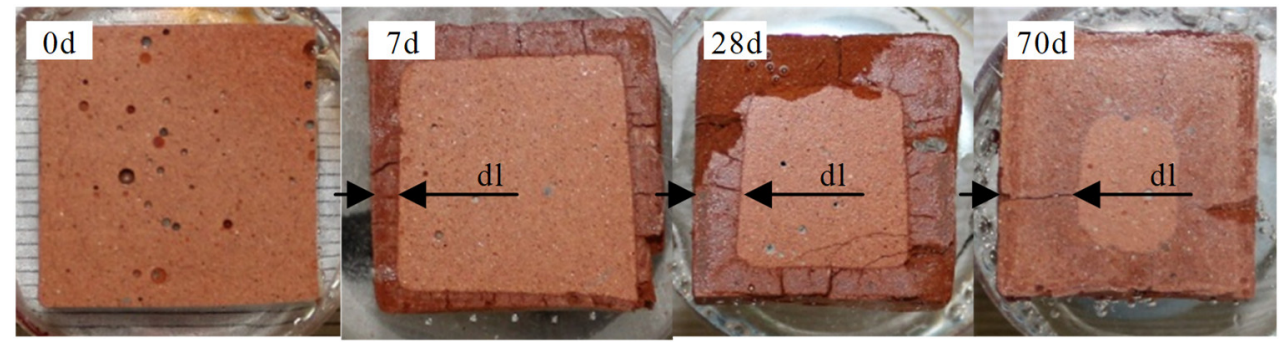

Figure 9. Epoxy embedded samples of geopolymers MK54 for measuring the eroded layer (el) and the deteriorated layer $(\mathrm{dl})$, before $(0 \mathrm{~d})$, and after sulfuric acid exposure $(7 \mathrm{~d}, 28 \mathrm{~d}$, and $70 \mathrm{~d})$.

The progress of the eroded (el) and deteriorated (dl) layer over the entire exposure period is presented in Figure 10. For MK54, relevant changes in the eroded layer happened within the first 28 days of acid exposure. After 28 days, the eroded layer remained constant, meaning that the dimension of the geopolymer sample did not change further.

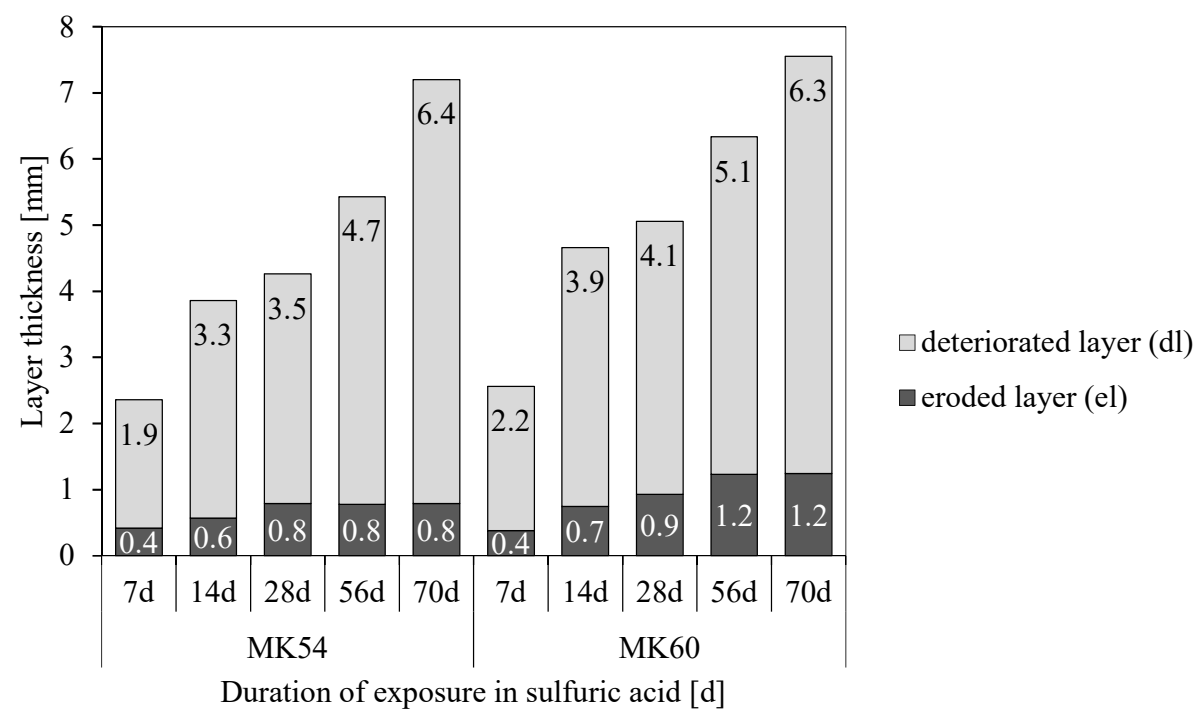

Figure 10. Thickness of eroded (el) and deteriorated (dl) layer of MK54 and MK60 after different exposure periods in sulfuric acid.

MK60 showed a similar trend, whereby a constant value $(1.2 \mathrm{~mm})$ of the eroded layer was reached after 56 days. For both geopolymers, the deteriorated layer increased continuously over the whole exposure period, with only minor differences between MK54 and MK60. The progress of deterioration could be subdivided into three stages. A steep rise in values up to 14 days of exposure (1st stage), a transition stage where the deterioration changes only slightly (2nd stage), and a moderate increase after 28 days (3rd stage).

\subsection{Powder X-ray Diffraction of Unexposed Specimen and Deteriorated Layer}

Comparing powder $\mathrm{X}$-ray diffraction patterns of unexposed geopolymers and the deteriorated layers of MK54 and MK60 reveal new crystalline phases (gypsum, alunogen, alum-(K)). These phases occur due to the exposure of specimens to sulfuric acid at $\mathrm{pH} 1$, as presented in Figure 11 for MK54 and the deteriorated layers after 7, 28, and 70 days of sulfuric acid exposure. 


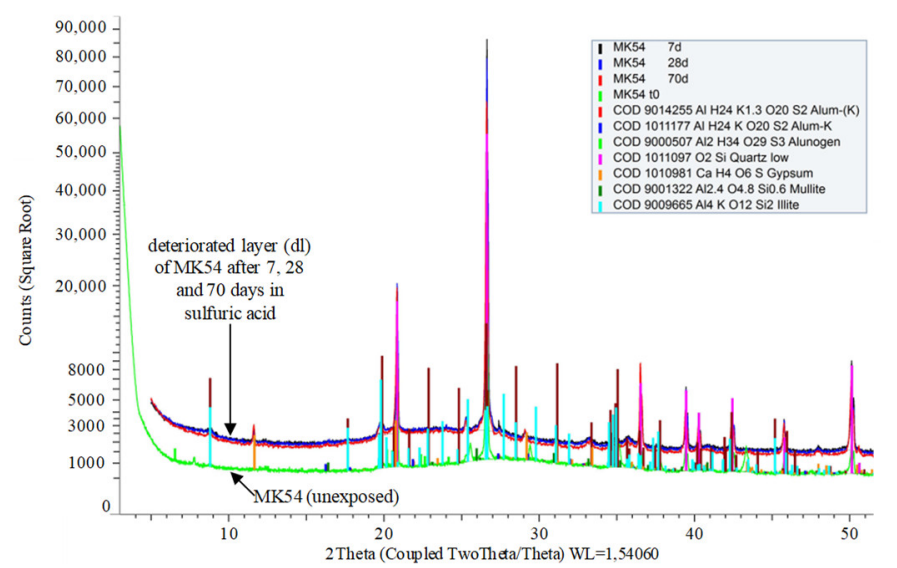

Figure 11. Characteristic parts of XRD patterns of unexposed geopolymer MK54 and deteriorated layers (dl) of MK54 after 7, 28, and 70 days of exposure to sulfuric acid.

Traces of mullite, illite, and quartz resulted from the mineralogical composition of the metakaolin. The newly built crystalline phases, gypsum, alunogen, and alum-(K), were detected in all deteriorated layers $(7,14,28,56$, and 70 days of acid exposure) of MK54 and MK60. Compared to the unexposed samples, XRD patterns of the deteriorated layers indicated a shift of the amorphous hump towards lower angle $2 \theta$, not showing a notable difference between different durations of sulfuric acid exposure for MK54 and MK60.

\subsection{SEM-EDX: Depth of Reaction DR(e)}

Figure 12 shows the results from EDX elemental mapping for potassium (MK54). The abscissa of the graph, representing the depth into the specimen, ran from $x=0 \mathrm{~mm}$ (original surface of the sample) to $x=10 \mathrm{~mm}$ (i.e., the core of the $20 \mathrm{~mm} \times 20 \mathrm{~mm}$ cross-section sample). Each curve (representing different exposure times in sulfuric acid) started at concentrations of about $0.5 \%$. These values were significantly lower than the percentages of the original unexposed sample, in Figure 12 represented by $\mathrm{ref}_{\min }(4.8 \%)$ and $\mathrm{ref}_{\max }(5.0 \%)$, demonstrating the leaching of potassium out of the geopolymer. The shift of the curves to the right represented the progress of the deteriorated layer, as described in Figures 2 and 3 .

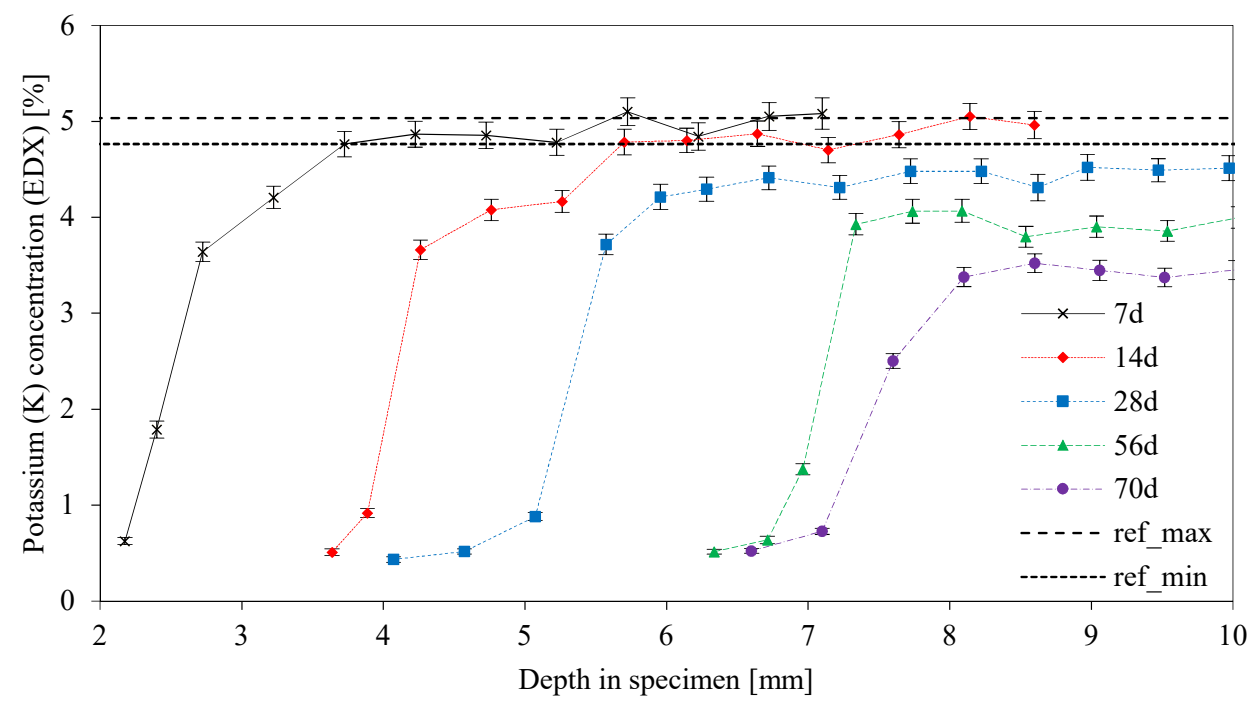

Figure 12. MK54 potassium concentration from EDX elemental mapping, as a function of depth in the specimen. Curves for different exposure times up to 70 days and reference lines ref min $_{\text {in }}$ and ref $f_{\max }$ from the original unexposed geopolymer sample. 
After 7 and 14 days of acid exposure, the ref $\mathrm{min}_{\min }$ concentration of the unexposed sample was reached again after a distance of approximately $2 \mathrm{~mm}$ from the end of DD. As a result of this, the leaching of potassium had not reached the core of the specimen. The maximum potassium concentration of sample $28 \mathrm{~d}(4.5 \%)$ did not reach ref $_{\min }$, indicating a partial leaching of potassium up to the core of the sample. The maximum potassium concentrations of the samples $56 \mathrm{~d}(4.1 \%)$ and $70 \mathrm{~d}(3.7 \%)$ showed that the leaching of potassium continued. Maximum potassium concentrations for $28 \mathrm{~d}, 56 \mathrm{~d}$, and $70 \mathrm{~d}$ samples of MK60 were 5.1\%, 4.6\%, and 3.7\%.

The Si concentration of MK54 is illustrated in Figure 13. Based on the measured Si concentrations, no leaching of this element could be detected, a fact that has already been discussed before, in the context of Figure 7. It was noticeable that all curves run above the ref ${ }_{\min }$ line, therefore representing percentages in the range of the original unexposed geopolymer. Furthermore, the percentages of $\mathrm{Si}$ were, in many cases, slightly higher than the percentage of ref $f_{\max }$, meaning that the Si concentration in some areas might be higher than the concentrations in the original values. As SEM-EDX measurements represented semi-quantitative values, the slightly higher Si concentrations of MK54 should not be interpreted as an accumulation of silicon-rich species, as mentioned by Sturm et al. [36].

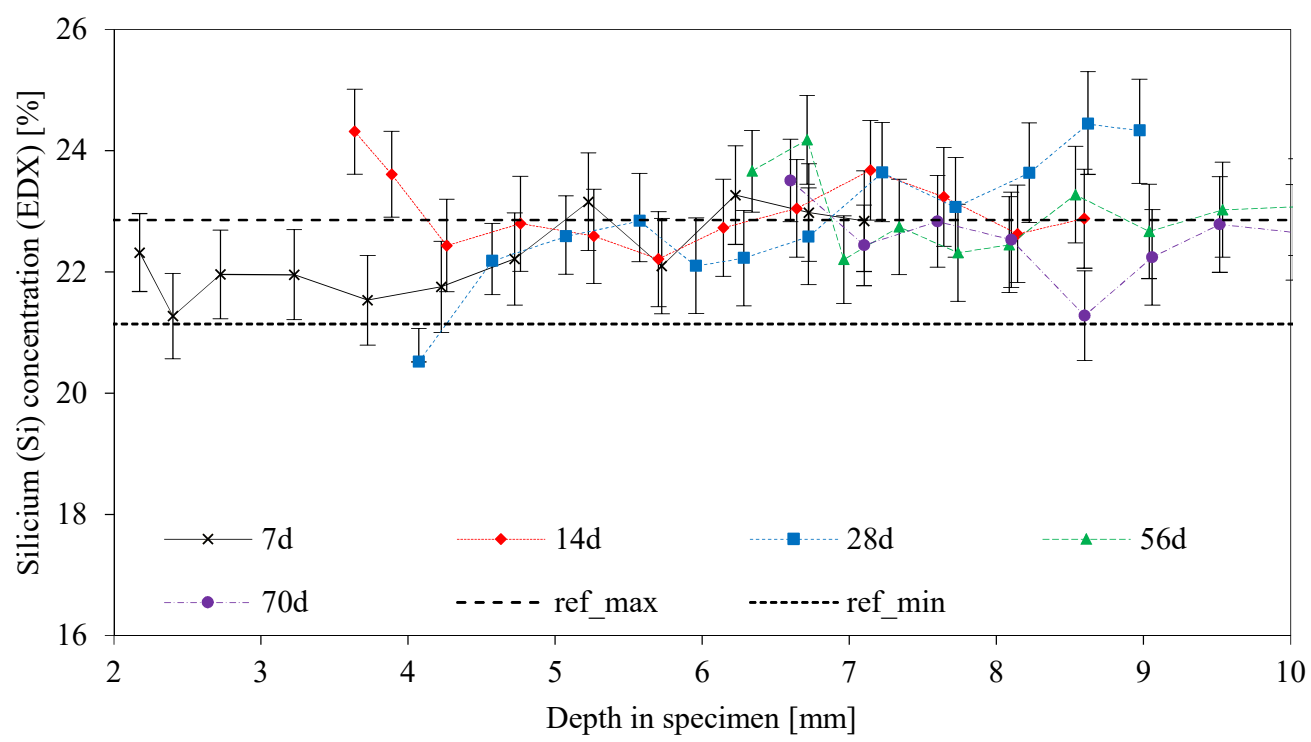

Figure 13. Silicon concentration from EDX elemental mapping, as a function of depth in the specimen. Curves for different exposure times up to 70 days and reference lines ref $_{\min }$ and ref $_{\max }$ from the original unexposed geopolymer sample.

$\mathrm{Al}$ concentrations as a function of the depth at the specimen (Figure 14) clearly showed the dealumination of a geopolymer as a result of the sulfuric acid attack. Starting at a concentration of approximately $4 \%$ (apart from sample $28 \mathrm{~d}$ ), the percentage range of the original unexposed sample with a minimum percentage of $8.43 \%\left(\mathrm{ref}_{\min }\right)$ and a maximum percentage of $9.17 \%\left(\mathrm{ref}_{\max }\right)$ was reached after 1-2 $\mathrm{mm}$, depending on the duration of sulfuric acid exposure. As the ref $\mathrm{min}_{\mathrm{m}}$ percentage was reached in all cases $(7,14,28,56$, and 70 days), the dealumination of the geopolymer had not reached the core of the specimens. The appearance of the curves was also very similar to the course of the K-concentration curves, which suggested a connection between $\mathrm{K}$ and $\mathrm{Al}$ leaching during the degradation process.

In order to better assess the semi-quantitative EDX results, $\mathrm{Si} / \mathrm{Al}$ ratios were calculated from the individual $\mathrm{Al}$ and $\mathrm{Si}$ elemental mapping results (Figure 15). The degradation of the geopolymer network led to changes in the $\mathrm{Si} / \mathrm{Al}$ ratio, as the $\mathrm{Al}$ percentages decrease due to the sulfuric acid attack and the Si percentages only slightly changed. Ratios in the interfacial transition zone between the deteriorated layer and visually intact core were in the range of $6-8$, reaching the range of the original sample $\left(\mathrm{ref}_{\min }, \mathrm{ref}_{\max }\right.$ ) within a distance of less than $1 \mathrm{~mm}$. Higher $\mathrm{Si} / \mathrm{Al}$ ratios were also reported by Bakharev [29] and Baščarević et al. [52]. 


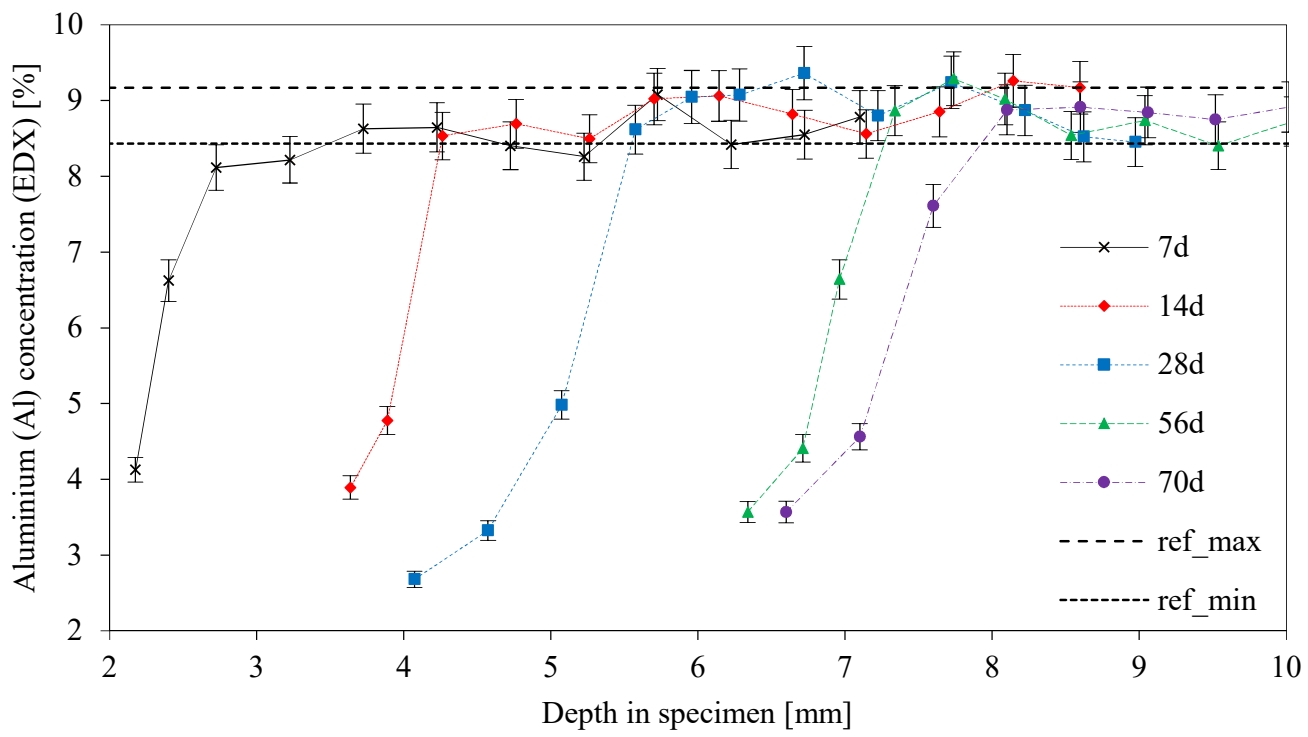

Figure 14. Aluminum concentration from EDX elemental mapping, as a function of depth in the specimen. Curves for different exposure times up to 70 days and reference lines ref min $_{\text {and }}$ ref max $_{\text {from }}$ the original unexposed geopolymer sample.

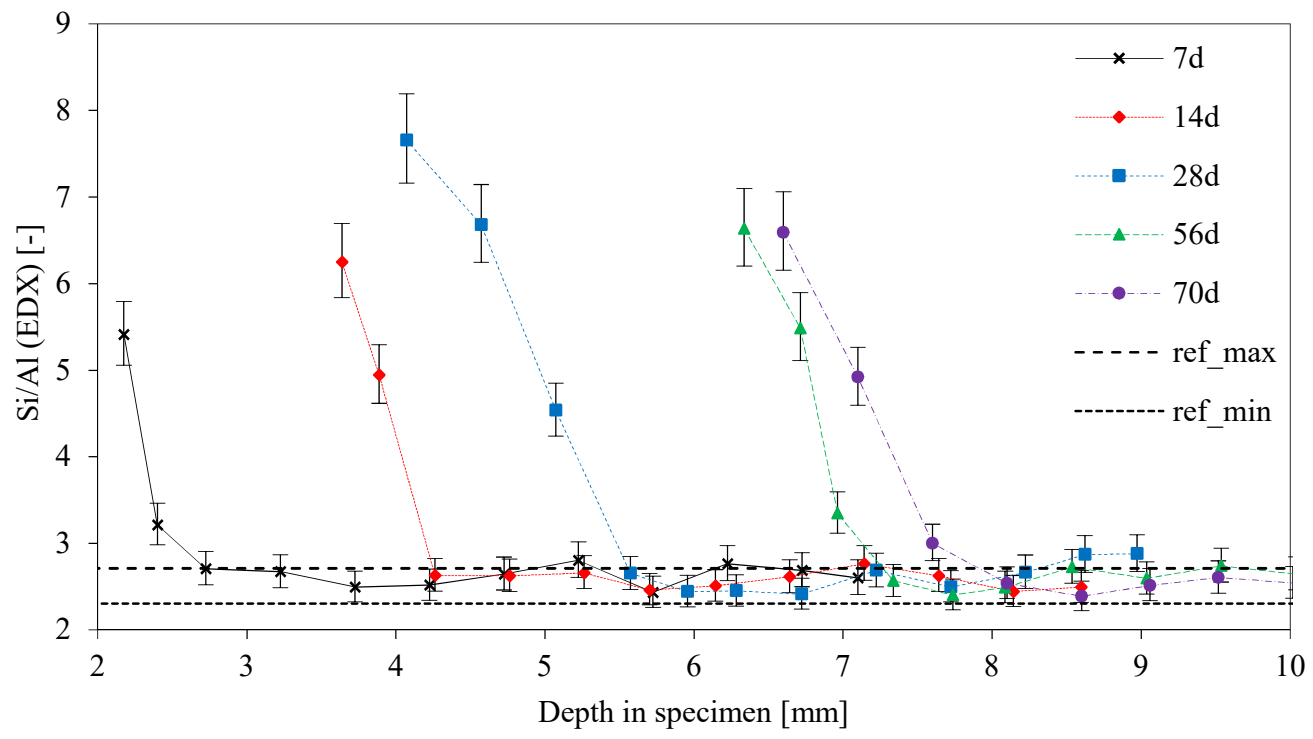

Figure 15. Si/Al ratios calculated by aluminum and silicon concentration from EDX elemental mapping, as a function of depth in the specimen. Curves for different exposure times up to 70 days and reference lines ref $_{\min }$ and $\mathrm{ref}_{\max }$ from the original unexposed geopolymer sample.

\section{Discussion}

The degradation of geopolymers in this study is investigated under the observed mechanisms of erosion (DE), deterioration (DD), and reaction (DR(e)), and the discussion of results, in particular, takes into account possible interactions between the three mechanisms. To enable this, DE, DD, DR(Al), and $\mathrm{DR}(\mathrm{K})$ are presented together in Figure 16 for MK54 and Figure 17 for MK60, where the latter has not been discussed yet, as all of the SEM-EDX results focused on MK54 so far. For MK54 and MK60, the thickness of the eroded layer increases to a certain value and stays more or less constant after 28 days of exposure (MK54) and 56 days of exposure (MK60), respectively. A reason for this could be the formation of the deteriorated layer. 


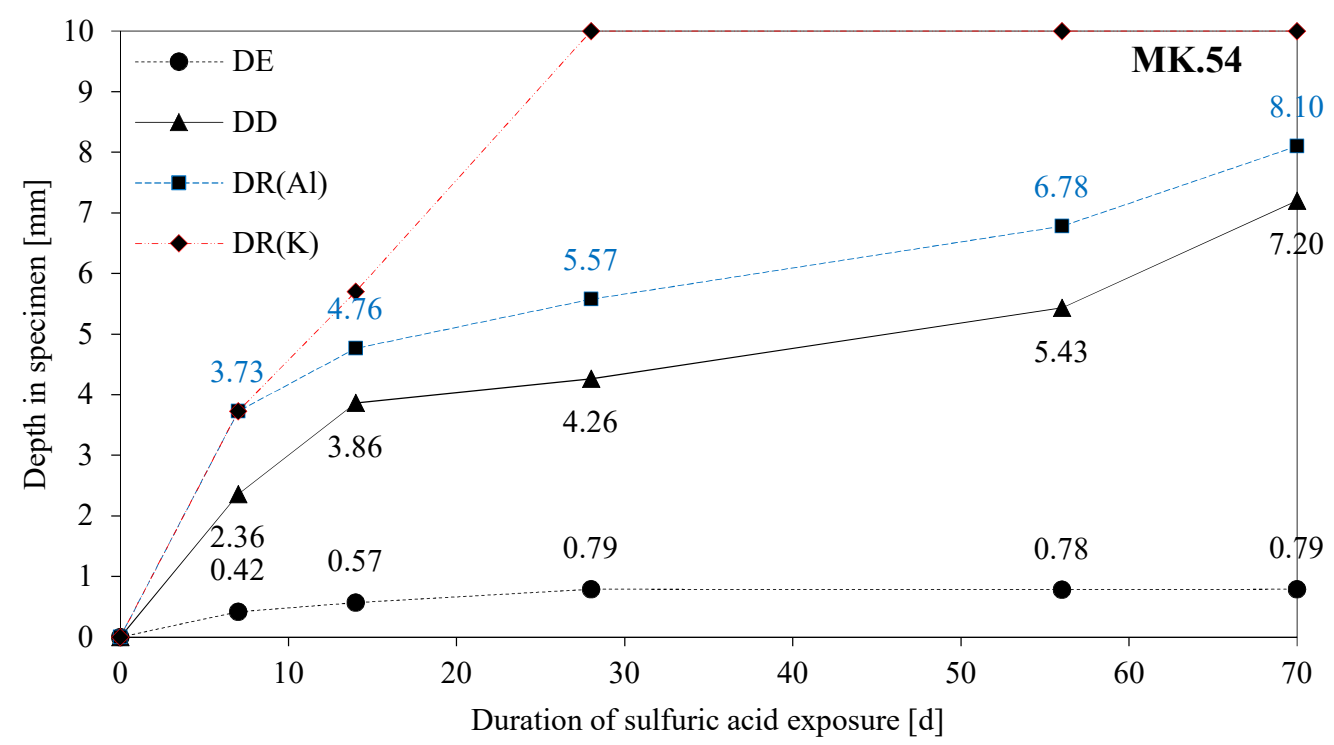

Figure 16. DE (depth of erosion), DD (depth of deterioration), and depth of reaction of aluminum $(\mathrm{DR}(\mathrm{Al}))$ and potassium $(\mathrm{DR}(\mathrm{K}))$ for MK54, as a function of the duration of exposure in sulfuric acid.

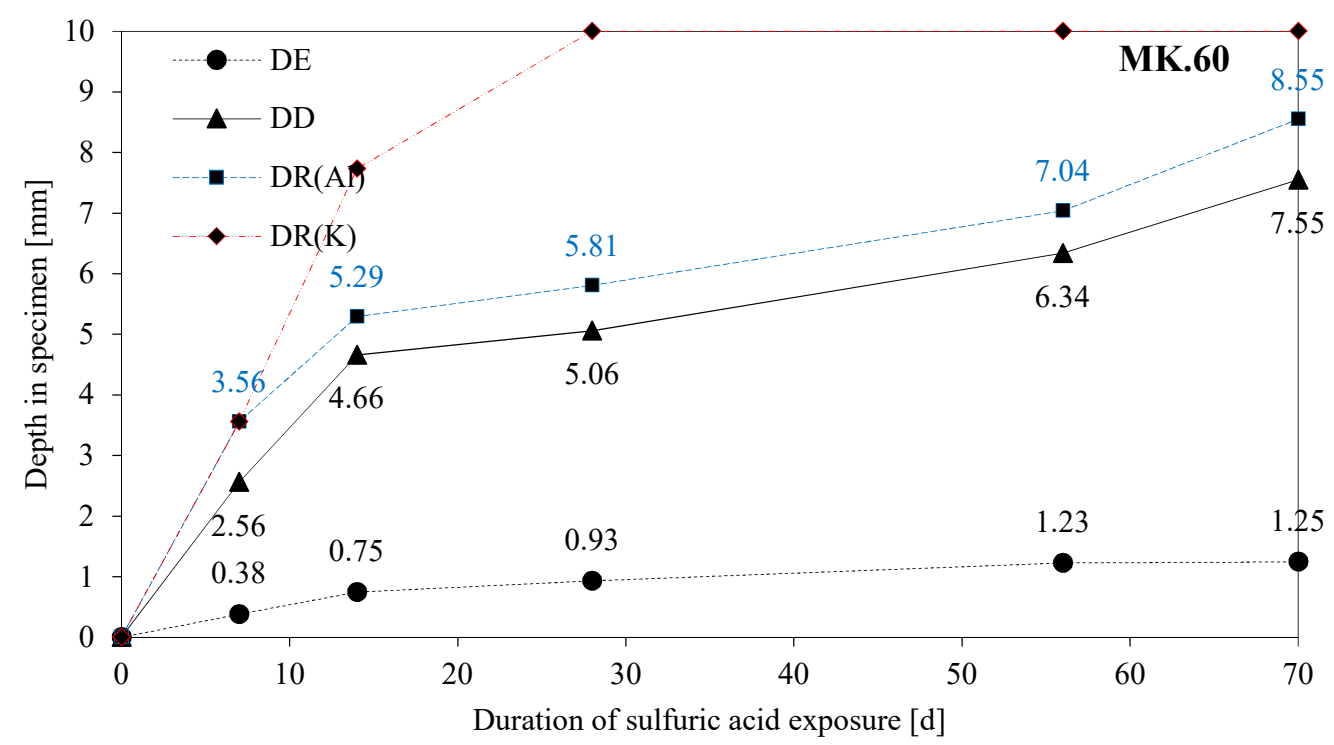

Figure 17. DE (depth of erosion), DD (depth of deterioration), and depth of reaction of aluminum $(\mathrm{DR}(\mathrm{Al}))$ and potassium $(\mathrm{DR}(\mathrm{K}))$ for MK60, as a function of the duration of exposure in sulfuric acid.

Lloyd et al. [40] tried to explain this by a two-stage degradation process, which is characterized by chemical reactions at the contact zone between sample and acid solution (1st stage) and a diffusion-controlled process (2nd stage), where the latter is resulting from the formation of a reaction layer which is degraded but not completely dissolved. This reaction layer, chemically stable in the range $\mathrm{pH} 1-3$, seems to act as a barrier but nevertheless cannot prevent further deterioration [40].

In the present study, the thickness of the deteriorated layer (dl) increases over the whole period of sulfuric acid exposure, meaning that physical (porosity and cracks) and chemical (leaching and dealumination) changes are an ongoing kinetically driven process with time. However, the gradient of the DD curve up to 14 days of acid attack is much steeper than the gradient after 14 days. The same effect can be observed at the DE curve. This is in agreement with the explanation given by Lloyd et al. [40], as the reaction layer, which is either the whole deteriorated layer (dl) itself or somewhere inside dl, slows down the deterioration as well as the erosion process. The fact that DE does not change after 28 days (MK54) and 56 days (MK60), respectively, and that DD gradually proceeds might be due to the 
stability of the reaction layer in the $\mathrm{pH}$ range of $1-3$. The increase of the DD curves after 56 days of exposure might be induced by the formation of cracks in the deteriorated layer, as the cracks will affect the diffusion barrier of the deteriorated layer and progresses the sulfuric acid faster and to a higher extent [63].

Comparing DE and DD of MK54 and MK60 shows that the erosion and deterioration process is progressing much faster for the geopolymer with the higher 1/s ratio (MK60). It can be stated, that in the present study the initial water content of the geopolymer, which influences porosity and pore size distribution of the hardened binder, is the decisive factor for the acid resistance of geopolymers. The higher $1 / \mathrm{s}$ ratio of MK60 results from the higher amounts of potassium silicate solution, which implicitly leads to a slight increase of the Si/Al ratio of the mixture (see Table 1). Due to the higher water amount of geopolymer MK60, a higher volume of pores remain in the hardened binder. Higher amounts of $\mathrm{Si}$ increases the resistance against acid attack [40,64], probably due to a denser network and a higher volume of geopolymer gel. Nevertheless, the better stability of geopolymers with higher $\mathrm{Si} / \mathrm{Al}$ ratios in acidic solutions also results from the deterioration process itself, namely the dealumination.

A network with $\mathrm{Si} / \mathrm{Al}=1$ contains only $\mathrm{Q}^{4}(4 \mathrm{Al})$ species, meaning that each $\mathrm{Si}$ atom is connected to four $\mathrm{Al}$ atoms by oxygen bridging bonds. In the case of dealumination (hydrolysis of $\mathrm{Si}-\mathrm{O}-\mathrm{Al}$ bonds), this leads to the complete destruction of the alumosilicate network [36]. At higher Si/Al ratios, more $\mathrm{Si}$ atoms are connected via bridging oxygens, which gives a residual stability of the matrix after dealumination, respectively less mass loss and higher residual strength [32].

As MK60 performed worse than MK54 in sulfuric acid, even with a higher Si/Al ratio, the porosity and pore size distribution must be the factor determining the degradation rate. The difference in total $\mathrm{Hg}$ intruded porosity (see Table 2) is only marginal, whereas the shift to bigger pores due to higher $1 / \mathrm{s}$ might be the decisive factor, a fact that Bakharev [29] and Lloyd et al. [40] observed as well.

The cracks in all of the samples' deteriorated layers and those present in the initial regions of the apparently intact core may also have an influence on the progress of corrosion. However, cracks were only detected after drying the specimens for subsequent sample preparation and EDX elemental mapping. As a consequence, no statements can be made about the effects of possible cracks.

Comparing DR(Al) and DR(K) in Figure 16 gives reason to believe what Lloyd et al. [40] described as a two-staged degradation process. The chemical reaction, in the present study the dealumination of the geopolymer, dominates the degradation process within the first seven days of exposure, as $\mathrm{DR}(\mathrm{Al})$ and $\mathrm{DR}(\mathrm{K})$ are almost identical after seven days of exposure. After 14 days, $\mathrm{DR}(\mathrm{K})$ has progressed deeper into the geopolymer sample than $\mathrm{DR}(\mathrm{Al})$, an effect that is even more pronounced for MK60. This indicates that the deterioration mechanisms after 14 days of exposure are diffusion-controlled, as the reduction of $\mathrm{K}$ concentration due to sulfuric acid intrusion progresses, although the dissolution of $\mathrm{Al}$ stops in shallower layers of the sample.

This fact is also discussed by considering the dissolution process. Leaching experiments with geopolymer powder, in many cases, reveal that the alkalis are most easily dissolved [51,62]. Regarding the alkalis, the leaching of $\mathrm{K}^{+}$from the geopolymer includes the exchange (or neutralization) of pore solution and the leaching from the charge balancing alkalis of the alumosilicate network [62]. As the neutralization probably will not affect the alumosilicate network of the geopolymer, so long as the drop in $\mathrm{pH}$ is not too severe, the concentration of $\mathrm{K}$ decreases further without a dealumination of the network. Even if the drop in $\mathrm{K}$ concentration results from leaching of $\mathrm{K}^{+}$from the charge balancing cations of the alumosilicate network, the possible cation exchange within the network could prevent the dealumination of the network. The cation exchange can be done by hydronium ions $\left(\mathrm{H}_{3} \mathrm{O}^{+}\right)$, which maintain the charge balance $[47,49,64]$.

The very similar curves of DD and $\mathrm{DR}(\mathrm{Al})$ prove, that the destruction of the geopolymer is caused by the dealumination of the alumosilicate network $[27,29]$ since the progress of DR(Al) precedes DD by approximately the same distance over the whole period of acid exposure. 
The curve of DD and DR(Al) with the large gradient within the first 14 days of exposure and the following drop of the gradient suggests, that some pore-blocking effects by newly formed species must have occurred. Formations of zeolites after the acid attack have been reported in previous publications [29,43], not mentioning a positive effect but rather a deterioration which led to a loss in mechanical strength. Furthermore, the calcium-containing zeolite Na-P1 (gismondine), which was detected by Bakharev [29], originated in the $\mathrm{CaO}$ content of the fly ash $(\mathrm{CaO}$ content $3.5 \%)$, the zeolites from the faujasite family detected by Palomo et al. [43] resulted from the exposure of metakaolin geopolymer in seawater and acetic acid.

Due to the dealumination and depolymerization of the network (breaking of $\mathrm{Si}-\mathrm{O}-\mathrm{Al}$ and $\mathrm{Si}-\mathrm{O}-\mathrm{Si}$ bonds), $\mathrm{Si}-\mathrm{OH}$ and $\mathrm{Al}-\mathrm{OH}$ groups in solution emerge [29]. At a very low $\mathrm{pH}$ of the acidic solution, a new condensation of polymeric ions rich in silica can follow the depolymerization of the alumosilicate network - the extent of the reaction depending on the source of alkaline activator and the temperature $[29,30]$. A pore-blocking effect and thus obstruction of a further acid attack, induced by precipitated silica, is mentioned by Sturm et al. [36], who also claim that the pore-blocking effect can only occur if the pores are small enough. Silicic acid as a new phase formed by the sulfuric acid exposure of the geopolymer was detected by Sturm et al. [36], Fernández-Jiménez et al. [30], and Bakharev [29]. Silicic acid $\left(\left(\mathrm{SiO}_{x}(\mathrm{OH})_{4-2 \mathrm{x}}\right)_{\mathrm{n}}\right)$ is most stable in the range of $\mathrm{pH} 2-3$ [65]. However, in the case of a supersaturated solution, amorphous silica can be formed as either colloidal particles, as precipitation, or as gel [29]. The change in gradients of the DD and DR(Al) curves in Figures 16 and 17 could be explained by such silica-rich, pore-blocking new phases. Under the assumption of an early pore-blocking effect, the deterioration would be slowed down, which could be the reason for the gradient change after 14 days of exposure. The newly precipitated silica phases arise from the breaking of $\mathrm{Si}-\mathrm{O}-\mathrm{Al}$ and $\mathrm{Si}-\mathrm{O}-\mathrm{Si}$ bonds. Furthermore, the SEM-EDX elemental mappings clearly revealed a decrease in $\mathrm{Al}$ - but not in Si-concentration. It can be concluded that the dissolved $\mathrm{Al}$ species diffuse towards the surface of the deteriorated layer and enter the sulfuric acid solution, whereas the dissolved Si species remain inside of the deteriorated layer.

Nevertheless, certain amounts of the dissolved $\mathrm{Al}$ will also form new phases and remain in the deteriorated layer, as the newly built aluminum sulfate mineral alunogen $\left(\mathrm{Al}_{2}\left(\mathrm{SO}_{4}\right)_{3} \cdot 17 \mathrm{H}_{2} \mathrm{O}\right)$ and the potassium aluminum sulfate mineral alum- $(\mathrm{K})\left(\mathrm{KAl}\left(\mathrm{SO}_{4}\right)_{2} \cdot 12 \mathrm{H}_{2} \mathrm{O}\right)$ in the XRD patterns of the deteriorated layers reveal. This could also lead to a pore-blocking effect. The low intensity of the gypsum peak in the XRD patterns of the deteriorated layers suggests, that even with a very low $\mathrm{CaO}$ content of the metakaolin, which is $0.8 \%$ [53], gypsum can be built. Whether this low amount has an influence on the pore-blocking effect or cracking of the deteriorated layer cannot be said with certainty. The shift of the amorphous hump in the XRD pattern, which is characteristic for the amorphous geopolymer gel, can be interpreted as the partially dissolved geopolymer gel, which has been previously reported by Zhang et al. [42].

Potassium concentrations from SEM-EDX elemental mapping of unexposed sample and sulfuric acid exposed samples are presented in Table 3. The minimum and maximum value for the unexposed sample originate from the mean percentage and corresponding absolute error. The minimum value of each acid exposed sample is the mean of the first elemental mapping taken after DD (see Figure 2). The maximum value of each acid exposed sample represent the highest mean value from elemental mappings taken further inside the core of exposed samples.

As already mentioned and shown in Figures 16 and 17, the potassium concentrations of the $7 \mathrm{~d}$ and $14 \mathrm{~d}$ samples reach the ref $_{\min }$ of the unexposed sample. For the samples $28 \mathrm{~d}, 56 \mathrm{~d}$, and $70 \mathrm{~d}$, the leaching of potassium reached the core of the sample which resulted in percentages lower than ref $_{\min }$. The $7 \mathrm{~d}$ and $14 \mathrm{~d}$ samples show approximate maximum values, the progress of leaching up to the core for longer durations of sulfuric acid exposure shows higher potassium percentages for MK60. MK54, with a lower amount of potassium silicate solution, contains fewer alkalis than MK60. The neutralization of the alkalinity in the geopolymer is therefore accelerated due to lower amounts of alkalis [37], which should reduce the degradation depth according to Lloyd et al. [40]. 
Under the assumption that the neutralization is the first step in the degradation process of geopolymers, MK60 should be more resistant against acid attack because more alkalis are present to neutralize the sulfuric acid solution. Nevertheless, comparing DD and DR(Al) in Figures 16 and 17 suggests the contrary, as for each exposure duration, DD and DR(Al) values of MK60 are higher than those of MK54.

Table 3. Minimum and maximum potassium percentage of unexposed and sulfuric acid exposed samples, from SEM-EDX elemental mapping.

\begin{tabular}{|c|c|c|c|c|c|c|c|c|c|c|c|c|}
\hline \multirow{3}{*}{ Name } & \multicolumn{12}{|c|}{ Potassium Percentage from SEM-EDX Elemental Mapping [\%] } \\
\hline & \multicolumn{2}{|c|}{ Unexposed } & \multicolumn{2}{|c|}{$7 \mathrm{~d}$} & \multicolumn{2}{|c|}{$14 \mathrm{~d}$} & \multicolumn{2}{|c|}{$28 \mathrm{~d}$} & \multicolumn{2}{|c|}{$56 \mathrm{~d}$} & \multicolumn{2}{|c|}{$70 \mathrm{~d}$} \\
\hline & ref $_{\min }$ & ref $_{\max }$ & Min & Max & Min & Max & Min & Max & Min & Max & Min & Max \\
\hline MK54 & 4.8 & 5.0 & 0.6 & 5.1 & 0.5 & 5.1 & 0.4 & 4.5 & 0.5 & 4.1 & 0.5 & 3.7 \\
\hline MK60 & 4.9 & 5.1 & 0.5 & 5.1 & 0.6 & 5.0 & 0.6 & 5.1 & 0.6 & 4.6 & 0.5 & 3.7 \\
\hline
\end{tabular}

Considering the two-stage degradation process from Lloyd et al. [40] and assuming that after 14 days of exposure a diffusion-controlled degradation mechanism dominates, the further increase of $\mathrm{DD}$ and $\mathrm{DR}(\mathrm{Al})$ are analyzed next. $\mathrm{DD}$ and $\mathrm{DR}(\mathrm{Al})$ of the $14 \mathrm{~d}$ sample and the percentage increase of DD and DR(Al) starting from 14d samples are listed in Table 4.

Table 4. DD and DR(Al) of $14 \mathrm{~d}$ sulfuric acid exposed geopolymer samples and the percentage increase of $\mathrm{DD}$ and $\mathrm{DR}(\mathrm{Al})$ starting from the $14 \mathrm{~d}$ exposed sample for exposed samples $28 \mathrm{~d}, 56 \mathrm{~d}$, and $70 \mathrm{~d}$.

\begin{tabular}{ccccccccc}
\hline \multirow{2}{*}{ Name } & \multicolumn{2}{c}{ 14 d Sample } & \multicolumn{3}{c}{ Percentage Increase, Starting from 14 d Percentage [\%] } \\
\cline { 2 - 9 } & \multicolumn{2}{c}{ [mm] } & \multicolumn{3}{c}{ DD } & \multicolumn{4}{c}{ DR(Al) } \\
\cline { 2 - 9 } & DD & DR(Al) & $\mathbf{2 8 ~ d}$ & $\mathbf{5 6 ~ d}$ & $\mathbf{7 0 ~ d}$ & $\mathbf{2 8 ~ d}$ & $\mathbf{5 6 ~ d}$ & $\mathbf{7 0 ~ d}$ \\
\hline MK54 & 3.9 & 4.8 & 10.4 & 40.7 & 86.5 & 17.0 & 42.4 & 70.2 \\
\hline MK60 & 4.7 & 5.3 & 8.6 & 36.1 & 62.0 & 9.8 & 33.1 & 61.6 \\
\hline
\end{tabular}

DD and DR(Al) of MK60 14 d sample progressed into deeper zones than in the case of MK54, however, the following percentage increase of DD and DR(Al) is less pronounced in the case of MK60. This may lead to the conclusion, that the chemical reaction (1st stage of degradation process) up to 14 days of exposure is most influenced by the higher porosity and the bigger pores of the geopolymer MK60, meaning there is less solid material in the bulk volume of the geopolymer that needs to be dissolved. The diffusion-controlled reaction (2nd stage of degradation process) after 14 days of exposure may be most influenced by the total amount of free alkalis in the pores of the geopolymer-a higher neutralization potential—which will slow down further degradation processes.

Although the above-mentioned statements on the two-stage degradation process are only hypotheses, they are in agreement with the clearly observable influence of porosity and pore size distribution. The porosity of (low $\mathrm{CaO})$ geopolymers is characterized by a high degree of connectivity [57] and depends mainly on the amount of water in the mixtures [57,66], the $\mathrm{Si} / \mathrm{Al}$ ratio of the network, and the type of alkaline activator solution $[67,68]$. However, due to the ink-bottle effect, mercury intruded pore size distribution does not represent the pore size but the pore entry size [69]. Therefore, larger pores are often not detected by MIP measurements, especially in the case of geopolymers [67]. This makes the correlation between the MIP pore size distribution and the degree and progress of degradation a difficult task.

\section{Conclusions}

Scanning electron microscopy with energy-dispersive X-ray spectroscopy (SEM-EDX) is a useful tool to semi-quantify the progress of sulfuric acid-induced degradation in geopolymer materials, especially when the element concentration curve within the corroded sample needs to be analyzed. 
The results of the two geopolymer mixtures with slightly different $1 / \mathrm{s}$ and $\mathrm{Si} / \mathrm{Al}$ ratios show significant differences in the degree of degradation. The results allow the following conclusions:

1. The depth of erosion (DE) of the acid exposed surface of specimens increases up to 28 days (MK54) and 56 days (MK60) without any relevant further increase in values after the aforementioned durations;

2. The gradient of the DD-curve (depth of deterioration) is steep up to 14 days of exposure with a lower gradient after that point. The same effect can be observed for the depth of reaction for aluminum (DR(Al));

3. The curve for the depth of reaction of potassium $(\mathrm{DR}(\mathrm{K}))$ is similar to the $\mathrm{DR}(\mathrm{Al})$ curve up to 7 days of exposure, with steeply rising values after 7 days;

4. The gradients of $\mathrm{DE}, \mathrm{DD}$, and $\mathrm{DR}(\mathrm{Al})$ indicate a two-stage degradation mechanism (initially chemically followed by a diffusion-controlled), as already proposed by Lloyd et al. [40];

5. The $\mathrm{DR}(\mathrm{K})$ and $\mathrm{DR}(\mathrm{Al})$ values indicate a leaching of potassium in the first step of degradation, followed by the dealumination and depolymerization of the geopolymer network;

6. Stronger deterioration of the MK60 sample within the first 14 days of exposure might be induced by the higher porosity and coarser pore size distribution of MK60;

7. After 14 days of exposure, the lower degradation rate (DR(Al) and $\mathrm{DD})$ of MK60 compared to MK54 might result from the diffusive controlled degradation mechanism after that time point and the higher amount of alkalis in the MK60 sample;

8. After sulfuric acid exposure, newly built (potassium) aluminum sulfate minerals in the deteriorated layer like alunogen and alum-(K) indicate a possible pore blocking effect.

Author Contributions: Conceptualization, O.V.; methodology: materials and processing, O.V.; SEM-EDX, C.B.; XRD, C.B., N.U.; Porosity (MIP), O.V.; discussion, O.V.; resources, E.K.; data curation, O.V.; writing-original paper preparation, O.V.; writing - review and editing, results and discussion, O.V., N.U., E.K.; visualization-all figures, O.V.; supervision, O.V., N.U. and E.K.; project administration, O.V. and E.K.; funding acquisition, E.K. All authors have read and agreed to the published version of the manuscript.

Funding: This research has been supported by TU Darmstadt, by the ZIM-AiF project "Development of chemical-resistant waste water pipes made of geopolymer concrete", funded by the Federal Ministry for Economic Affairs and Energy, Germany.

Acknowledgments: We acknowledge support by the German Research Foundation and the Open Access Publishing Fund of Technical University of Darmstadt

Conflicts of Interest: The authors declare no conflict of interest. The funders had no role in the design of the study, in the collection, analyses, or interpretation of data, in the writing of the manuscript, or in the decision to publish the results.

\section{References}

1. Duxson, P.; Fernández-Jiménez, A.; Provis, J.L.; Lukey, G.C.; Palomo, A.; Van Deventer, J.S.J. Geopolymer technology: The current state of the art. J. Mater. Sci. 2006, 42, 2917-2933. [CrossRef]

2. Buchwald, A.; Zellmann, H.-D.; Kaps, C. Condensation of aluminosilicate gels-model system for geopolymer binders. J. Non-Cryst. Solids 2011, 357, 1376-1382. [CrossRef]

3. Sun, W.; Zhang, Y.; Lin, W.; Liu, Z.-Y. In situ monitoring of the hydration process of K-PS geopolymer cement with ESEM. Cem. Concr. Res. 2004, 34, 935-940. [CrossRef]

4. De Silva, P.; Sagoe-Crenstil, K.; Sirivivatnanon, V. Kinetics of geopolymerization: Role of Al2O3 and SiO2. Cem. Concr. Res. 2007, 37, 512-518. [CrossRef]

5. Lloyd, R.R.; Provis, J.L.; Van Deventer, J.S. Pore solution composition and alkali diffusion in inorganic polymer cement. Cem. Concr. Res. 2010, 40, 1386-1392. [CrossRef]

6. Loewenstein, W. The distribution of aluminum in the tetrahedra of silicates and aluminates. Am. Miner. J. Earth Planet. Mater. 1954, 39, 92-96.

7. Fernández-Jiménez, A.; Palomo, A.; Sobrados, I.; Sanz, J. The role played by the reactive alumina content in the alkaline activation of fly ashes. Microporous Mesoporous Mater. 2006, 91, 111-119. [CrossRef] 
8. Dong, T.; Xie, S.; Wang, J.; Chen, Z.; Liu, Q. Properties and characterization of a metakaolin phosphate acid-based geopolymer synthesized in a humid environment. J. Aust. Ceram. Soc. 2020, 56, 175-184. [CrossRef]

9. Zhang, B.; Guo, H.; Yuan, P.; Deng, L.; Zhong, X.; Li, Y.; Wang, Q.; Liu, D. Novel acid-based geopolymer synthesized from nanosized tubular halloysite: The role of precalcination temperature and phosphoric acid concentration. Cem. Concr. Compos. 2020, 110, 103601. [CrossRef]

10. Puertas, F.; Fernández-Jiménez, A. Mineralogical and microstructural characterisation of alkali-activated fly ash/slag pastes. Cem. Concr. Compos. 2003, 25, 287-292. [CrossRef]

11. Yip, C.; Lukey, G.; Van Deventer, J. The coexistence of geopolymeric gel and calcium silicate hydrate at the early stage of alkaline activation. Cem. Concr. Res. 2005, 35, 1688-1697. [CrossRef]

12. Shi, C.; Wu, X.; Tang, M. Hydration of alkali-slag cements at $150{ }^{\circ}$ C. Cem. Concr. Res. 1991, 21, 91-100. [CrossRef]

13. Wang, S.-D.; Scrivener, K.L. Hydration products of alkali activated slag cement. Cem. Concr. Res. 1995, 25, 561-571. [CrossRef]

14. Palomo, A.; Fernández-Jiménez, A.; Criado, M. "Geopolymers": Same basic chemistry, different microstructures. Mater. Constr. 2004, 54,77-91. [CrossRef]

15. Pacheco-Torgal, F. Introduction to Handbook of Alkali-activated Cements, Mortars and Concretes. In Handbook of Alkali-Activated Cements, Mortars and Concretes; Elsevier BV: Amsterdam, The Netherlandscity, 2015; pp. 1-16.

16. Krivenko, P. Alkaline cements: Terminology, classification, aspects of durability. 1997.

17. Hermmann, A.; König, A.; Dehn, F. Vorschlag zur Klassifizierung von alkalisch-aktivierten Bindemitteln und Geopolymer-Bindemitteln. Beton Fachz. Für Bau Tech. 2015, 7+8, 390-395.

18. Xu, H.; Van Deventer, J.S. Microstructural characterisation of geopolymers synthesised from kaolinite/stilbite mixtures using XRD, MAS-NMR, SEM/EDX, TEM/EDX, and HREM. Cem. Concr. Res. 2002, 32, 1705-1716. [CrossRef]

19. Barbosa, V.F.; MacKenzie, K.J. Synthesis and thermal behaviour of potassium sialate geopolymers. Mater. Lett. 2003, 57, 1477-1482. [CrossRef]

20. Olmstead, W.; Hamlin, H. Converting portions of the Los Angeles outfall sewer into a septic tank. Eng. News 1900, 44, 317-318.

21. Koenig, A.; Dehn, F. Biogenic acid attack on concretes in biogas plants. Biosyst. Eng. 2016, 147, $226-237$. [CrossRef]

22. Scheydt, J.C. Mechanismen der Korrosion bei Ultrahochfestem Beton; KIT Scientific Publishing: Karlsruhe, Germany, 2014; Volume 74.

23. Hüttl, R.; Hillemeier, B. Hochleistungsbeton-Beispiel Säureresistenz. Betonw. Fertil.-Tech 2000, 1, 52-60.

24. Mosebach, H.; Stengel, F. Hochleistungsbeton mit hoher Chemischer Beständigkeit; Beton: Erkrath, Germany, 2010.

25. Roberts, D.; Nica, D.; Zuo, G.; Davis, J. Quantifying microbially induced deterioration of concrete: Initial studies. Int. Biodeterior. Biodegrad. 2002, 49, 227-234. [CrossRef]

26. Fernández-Jiménez, A.; Palomo, A. Chemical durability of geopolymers. In Geopolymers; Elsevier BV: Amsterdam, The Netherlands, 2009; pp. 167-193.

27. Ukrainczyk, N.; Muthu, M.; Vogt, O.; Koenders, E. Geopolymer, Calcium Aluminate, and Portland Cement-Based Mortars: Comparing Degradation Using Acetic Acid. Materials 2019, 12, 3115. [CrossRef] [PubMed]

28. Koenig, A.; Herrmann, A.; Overmann, S.; Dehn, F. Resistance of alkali-activated binders to organic acid attack: Assessment of evaluation criteria and damage mechanisms. Constr. Build. Mater. 2017, 151, 405-413. [CrossRef]

29. Bakharev, T. Resistance of geopolymer materials to acid attack. Cem. Concr. Res. 2005, 35, 658-670. [CrossRef]

30. Fernandez-Jimenez, A.; García-Lodeiro, I.; Palomo, A. Durability of alkali-activated fly ash cementitious materials. J. Mater. Sci. 2006, 42, 3055-3065. [CrossRef]

31. Song, X.; Marosszeky, M.; Brungs, M.; Munn, R. Durability of fly ash based geopolymer concrete against sulphuric acid attack. In Proceedings of the International Conference on Durability of Building Materials and Components, Lyon, France, 17-20 April 2005; pp. 369-375.

32. Okoye, F.N.; Prakash, S.; Singh, N.B. Durability of fly ash based geopolymer concrete in the presence of silica fume. J. Clean. Prod. 2017, 149, 1062-1067. [CrossRef] 
33. Kwasny, J.; Aiken, T.A.; Soutsos, M.N.; McIntosh, A.J.; Cleland, D.J. Comparison of Lithomarge and Cement-Based Mortars Performance in Aggressive Aqueous Environments. In Proceedings of the Sixth International Conference on Durability of Concrete Structures, Leeds, UK, 18-20 July 2018.

34. Dutta, A.; Moharana, N.C. Mechanical and Durability Properties of Fly Ash-Based Geopolymer Concrete. In Recent Developments in Sustainable Infrastructure; Springer: Singapore, 2020; pp. 699-717.

35. Grengg, C.; Ukrainczyk, N.; Koraimann, G.; Mueller, B.; Dietzel, M.; Mittermayr, F. Long-term in situ performance of geopolymer, calcium aluminate and Portland cement-based materials exposed to microbially induced acid corrosion. Cem. Concr. Res. 2020, 131, 106034. [CrossRef]

36. Sturm, P.; Gluth, G.; Jäger, C.; Brouwers, H.; Kühne, H.-C. Sulfuric acid resistance of one-part alkali-activated mortars. Cem. Concr. Res. 2018, 109, 54-63. [CrossRef]

37. Thokchom, S.; Ghosh, P.; Ghosh, S. Acid resistance of fly ash based geopolymer mortars. Int. J. Recent Trends Eng. 2009, 1, 36.

38. Sun, P.; Wu, H.-C. Chemical and freeze-thaw resistance of fly ash-based inorganic mortars. Fuel 2013, 111, 740-745. [CrossRef]

39. Thokchom, S. Fly ash geopolymer pastes in sulphuric acid. Int. J. Eng. Innov. Res. 2014, 3, 943-947.

40. Lloyd, R.R.; Provis, J.L.; Van Deventer, J.S.J. Acid resistance of inorganic polymer binders. 1. Corrosion rate. Mater. Struct. 2012, 45, 1-14. [CrossRef]

41. Ariffin, M.; Bhutta, M.; Hussin, M.; Tahir, M.M.; Aziah, N. Sulfuric acid resistance of blended ash geopolymer concrete. Constr. Build. Mater. 2013, 43, 80-86. [CrossRef]

42. Zhang, M.; Zhao, M.; Zhang, G.; Mann, D.; Lumsden, K.; Tao, M. Durability of red mud-fly ash based geopolymer and leaching behavior of heavy metals in sulfuric acid solutions and deionized water. Constr. Build. Mater. 2016, 124, 373-382. [CrossRef]

43. Palomo, A.; Blanco-Varela, M.; Granizo, M.; Puertas, F.; Vazquez, T.; Grutzeck, M. Chemical stability of cementitious materials based on metakaolin. Cem. Concr. Res. 1999, 29, 997-1004. [CrossRef]

44. Duan, P.; Yan, C.; Zhou, W.; Luo, W.; Shen, C. An investigation of the microstructure and durability of a fluidized bed fly ash-metakaolin geopolymer after heat and acid exposure. Mater. Des. 2015, 74, 125-137. [CrossRef]

45. Zhuang, H.J.; Zhang, H.Y.; Xu, H. Resistance of geopolymer mortar to acid and chloride attacks. Procedia Eng. 2017, 210, 126-131. [CrossRef]

46. Temuujin, J.; Minjigmaa, A.; Lee, M.; Chen-Tan, N.; Van Riessen, A. Characterisation of class F fly ash geopolymer pastes immersed in acid and alkaline solutions. Cem. Concr. Compos. 2011, 33, 1086-1091. [CrossRef]

47. Burciaga-Díaz, O.; Escalante-García, J.I. Strength and Durability in Acid Media of Alkali Silicate-Activated Metakaolin Geopolymers. J. Am. Ceram. Soc. 2012, 95, 2307-2313. [CrossRef]

48. Monique, T.T.; Julien, S.; Sylvie, R. Durability of tubular geopolymer reinforced with silica sand. New J. Glass Ceram. 2012, 2012, 18601.

49. Gao, X.X.; Michaud, P.; Joussein, E.; Rossignol, S. Behavior of metakaolin-based potassium geopolymers in acidic solutions. J. Non-Cryst. Solids 2013, 380, 95-102. [CrossRef]

50. Bouguermouh, K.; Bouzidi, N.; Mahtout, L.; Pérez-Villarejo, L.; Martínez-Cartas, M.L. Effect of acid attack on microstructure and composition of metakaolin-based geopolymers: The role of alkaline activator. J. Non-Cryst. Solids 2017, 463, 128-137. [CrossRef]

51. Aly, Z.; Vance, E.R.; Perera, D.S.; Hanna, J.; Griffith, C.; Davis, J.; Durce, D. Aqueous leachability of metakaolin-based geopolymers with molar ratios of $\mathrm{Si} / \mathrm{Al}=1.5-4$. J. Nucl. Mater. 2008, 378, 172-179. [CrossRef]

52. Baščarević, Z.; Komljenović, M.; Miladinović, Z.; Nikolić, V.; Marjanović, N.; Žujović, Z.; Petrović, R. Effects of the concentrated NH4NO3 solution on mechanical properties and structure of the fly ash based geopolymers. Constr. Build. Mater. 2013, 41, 570-579. [CrossRef]

53. Vogt, O.; Ukrainczyk, N.; Ballschmiede, C.; Koenders, E. Vogt Reactivity and Microstructure of Metakaolin Based Geopolymers: Effect of Fly Ash and Liquid/Solid Contents. Materials 2019, 12, 3485. [CrossRef]

54. Deutsches Institut für Normung. DIN EN 196-1:2016-11, Prüfverfahren für Zement-Teil 1: Bestimmung der Festigkeit; Deutsche Fassung EN 196-1:2016; Deutsches Institut für Normung: Berlin, Germany, 2016.

55. Koenig, A.; Dehn, F. Main considerations for the determination and evaluation of the acid resistance of cementitious materials. Mater. Struct. 2016, 49, 1693-1703. [CrossRef] 
56. Goldstein, J.I.; Newbury, D.E.; Michael, J.R.; Ritchie, N.W.; Scott, J.H.J.; Joy, D.C. Scanning Electron Microscopy and X-ray Microanalysis; Springer: New York City, NY, USA, 2017.

57. Benavent, V.; Frizon, F.; Poulesquen, A. Effect of composition and aging on the porous structure of metakaolin-based geopolymers. J. Appl. Cryst. 2016, 49, 2116-2128. [CrossRef]

58. Ko, M.-S.; Chen, H.-Y.; Lyu, S.-J.; Wang, T.; Ueng, T.-H. Permeation characteristics and impact factors of geopolymers made of kaolin. Constr. Build. Mater. 2015, 93, 301-308. [CrossRef]

59. Tchakoute, H.; Rüscher, C.; Djobo, J.; Kenne, B.; Njopwouo, D. Influence of gibbsite and quartz in kaolin on the properties of metakaolin-based geopolymer cements. Appl. Clay Sci. 2015, 107, 188-194. [CrossRef]

60. Schmücker, M.; MacKenzie, K.J. Microstructure of sodium polysialate siloxo geopolymer. Ceram. Int. 2005, 31, 433-437. [CrossRef]

61. Barbosa, V.F.; MacKenzie, K.J. Thermal behaviour of inorganic geopolymers and composites derived from sodium polysialate. Mater. Res. Bull. 2003, 38, 319-331. [CrossRef]

62. Aly, Z.; Vance, E.; Perera, D. Aqueous dissolution of sodium aluminosilicate geopolymers derived from metakaolin. J. Nucl. Mater. 2012, 424, 164-170. [CrossRef]

63. Allahverdi, A.; Skvara, F. Nitric acid attack on hardened paste of geopolymeric cements, Part 1. Ceram. Silik. 2001, 45, 81-88.

64. Breck, D.W. Zeolite Molecular Sieves: Structure, Chemistry and Use; Krieger: Malabar, Florida, USA, 1984.

65. Iler, R.K. The Colloid Chemistry of Silica and Silicates; LWW: Philadelphia, PA, USA, 1955; Volume 80.

66. Latella, B.A.; Perera, D.; Durce, D.; Mehrtens, E.G.; Davis, J. Mechanical properties of metakaolin-based geopolymers with molar ratios of $\mathrm{Si} / \mathrm{Al} \approx 2$ and $\mathrm{Na} / \mathrm{Al} \approx 1$. J. Mater. Sci. 2008, 43, 2693-2699. [CrossRef]

67. Nguyen, Q.H.; Lorente, S.; Duhart-Barone, A.; LaMotte, H. Porous arrangement and transport properties of geopolymers. Constr. Build. Mater. 2018, 191, 853-865. [CrossRef]

68. Steins, P.; Poulesquen, A.; Frizon, F.; Diat, O.; Jestin, J.; Causse, J.; Lambertin, D.; Rossignol, S. Effect of aging and alkali activator on the porous structure of a geopolymer. J. Appl. Cryst. 2014, 47, 316-324. [CrossRef]

69. Berodier, E.; Bizzozero, J.; Muller, A. Mercury intrusion porosimetry. In A Practical Guide to Microstructural Analysis of Cementitious Materials; London, UK, 2016; Volume 419.

(C) 2020 by the authors. Licensee MDPI, Basel, Switzerland. This article is an open access article distributed under the terms and conditions of the Creative Commons Attribution (CC BY) license (http://creativecommons.org/licenses/by/4.0/). 